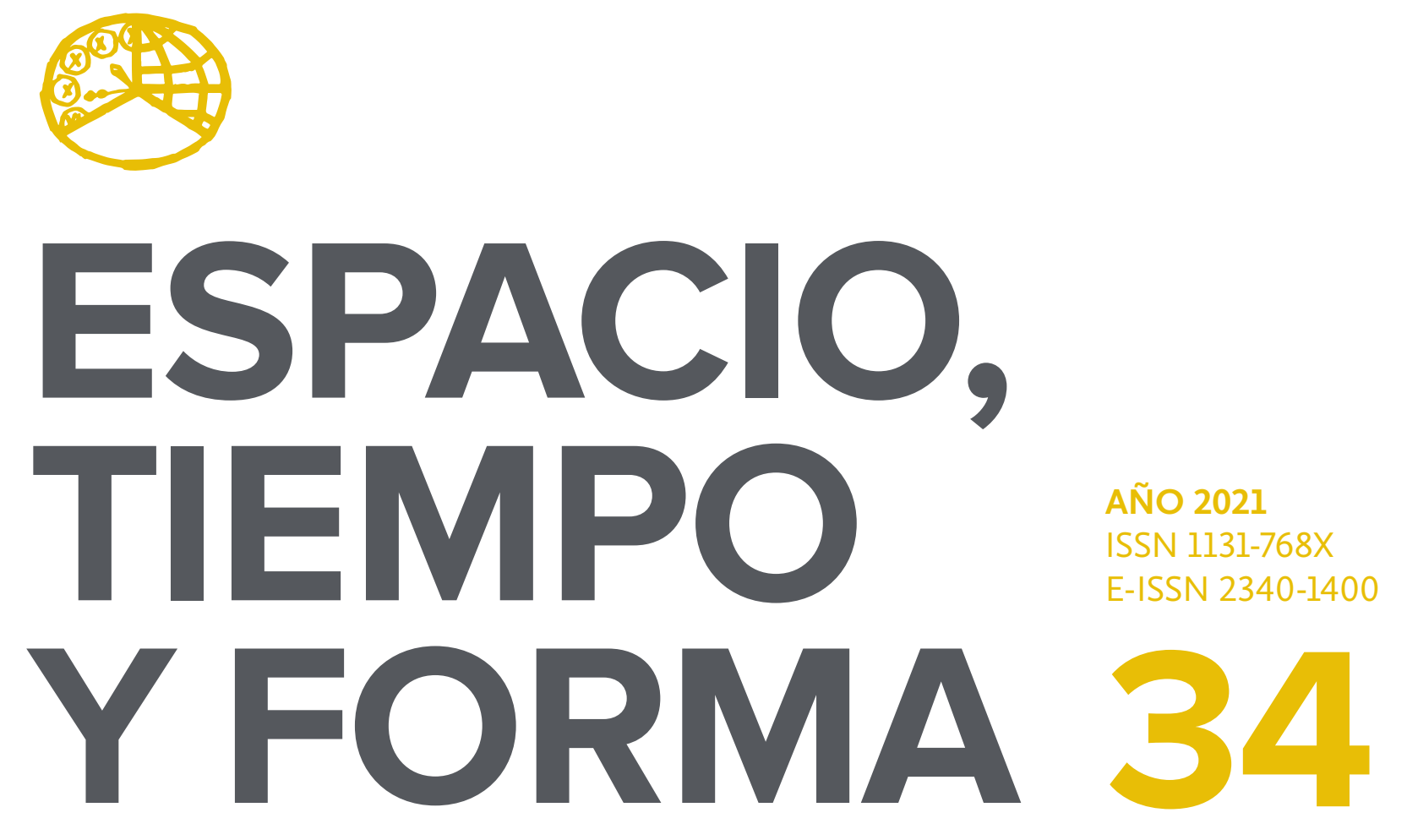

SERIE IV HISTORIA MODERNA

REVISTA DE LA FACULTAD DE GEOGRAFÍA E HISTORIA

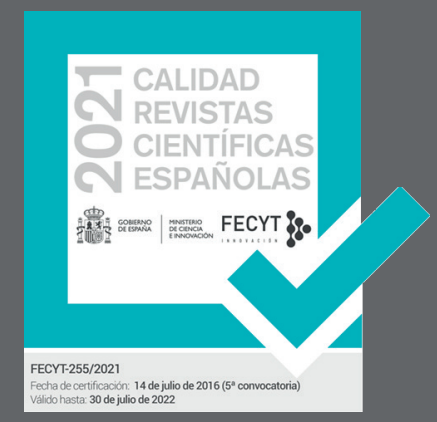




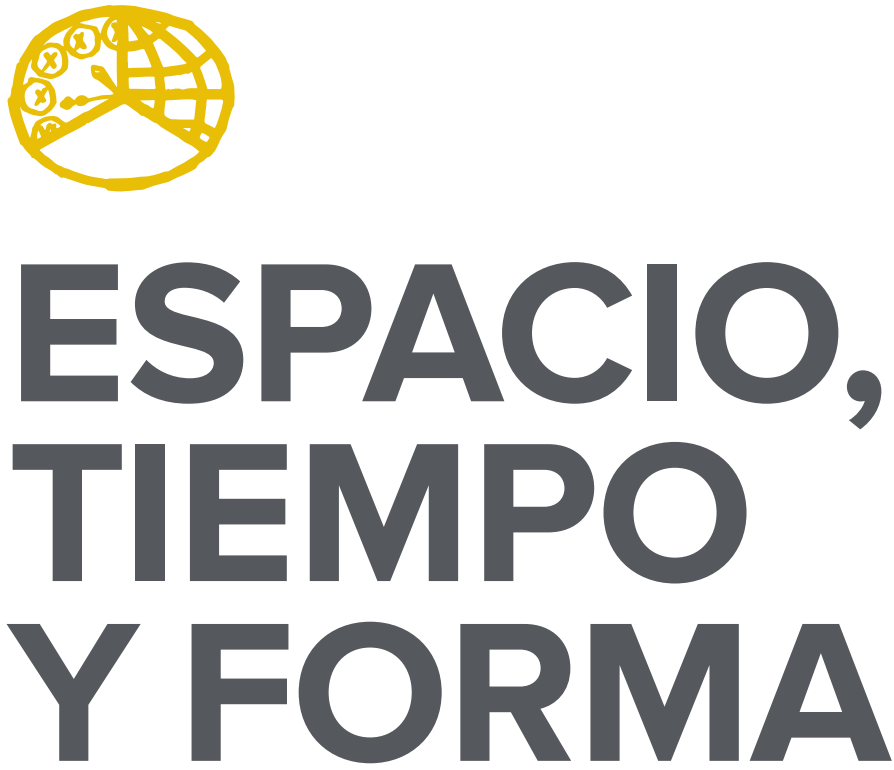

AÑO 2021

ISSN 1131-768X

E-ISSN 2340-1400

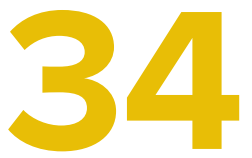

SERIE IV HISTORIA MODERNA

REVISTA DE LA FACULTAD DE GEOGRAFÍA E HISTORIA

DOI: https://doi.org/10.5944/etfiv.34.2021

\section{UกED}

UNIVERSIDAD NACIONAL DE EDUCACIÓN A DISTANCIA 
La revista Espacio, Tiempo y Forma (siglas recomendadas: ETF), de la Facultad de Geografía e Historia de la UNED, que inició su publicación el año 1988, está organizada de la siguiente forma:

$$
\begin{aligned}
& \text { SERIE I - Prehistoria y Arqueología } \\
& \text { SERIE II - Historia Antigua } \\
& \text { SERIE III - Historia Medieval } \\
& \text { SERIE IV - Historia Moderna } \\
& \text { SERIE V - Historia Contemporánea } \\
& \text { SERIE VI - Geografía } \\
& \text { SERIE VII - Historia del Arte }
\end{aligned}
$$

Excepcionalmente, algunos volúmenes del año 1988 atienden a la siguiente numeración:

$$
\begin{aligned}
& \mathrm{N} .^{\circ} 1 \text { - Historia Contemporánea } \\
& \mathrm{N}^{\circ} 2 \text { - Historia del Arte } \\
& \mathrm{N} .^{\circ} 3 \text { - Geografía } \\
& \mathrm{N} .^{\circ} 4 \text { - Historia Moderna }
\end{aligned}
$$

ETF no se solidariza necesariamente con las opiniones expresadas por los autores.

\author{
UNIVERSIDAD NACIONAL DE EDUCACIÓN A DISTANCIA \\ Madrid, 2021 \\ SERIE IV · HISTORIA MODERNA N. ${ }^{\circ} 34,2021$ \\ ISSN $1131-768 X \cdot$ E-ISSN 2340-1400 \\ DEPÓSITO LEGAL \\ M-21.037-1988 \\ URL \\ ETF IV · HISTORIA MODERNA · http://revistas.uned.es/index.php/ETFIV \\ DISEÑO Y COMPOSICIÓN \\ Carmen Chincoa Gallardo · http://www.laurisilva.net/cch \\ Impreso en España · Printed in Spain
}

(c) (7) (8) Esta obra está bajo una licencia Creative Commons Reconocimiento-NoComercial 4.0 Internacional. 


\section{MISCELÁNEA • MISCELLANY}





\title{
DEL MANUSCRITO A LA IMPRESIÓN: UN ESTUDIO DE LA TRAYECTORIA DE DOS PANEGÍRICOS ATRIBUIDOS A JOÃO DE BARROS
}

\section{FROM MANUSCRIPT TO PRINT: A STUDY OF THE TRAJECTORY OF TWO PANEGYRICS ATTRIBUTED TO JOÃO DE BARROS}

\author{
Fernando Altoé \\ Recibido: 21/01/2021 - Aceptado: 28/09/2021 \\ DOI: https://doi.org/10.5944/etfiv.34.2021.29485
}

\section{Resumen}

Este artículo presenta una investigación sobre la trayectoria de dos panegíricos atribuidos al académico portugués João de Barros. Leídos en el siglo XVI, el Panegírico de D. João III y el Panegírico da infanta D. Maria fueron publicados siglos más tarde: el primero en el siglo XVIIl por José Barbosa, y el segundo en el siglo XVII por Manuel Severim de Faria. En vista del largo intervalo que separa las publicaciones, buscamos de entender los acontecimientos, contextos y circunstancias que llevaron a su impresión, como expresión de un trabajo cruzado de varios agentes, así como la serie de eventos relacionados con la producción de sus sentidos como objetos.

Palabras clave

João de Barros; Panegírico; Trayectoria documental; Manuscritos; Impresos

\section{Abstract}

This article presents research on the trajectory of two panegyrics attributed to the Portuguese scholar João de Barros. Read in the $\mathrm{I} 6^{\text {th }}$ century, the Panegírico de D. João IIl and the Panegírico da infanta D. Maria were published centuries later: the first in the $18^{\text {th }}$ century by José Barbosa, and the second in the $17^{\text {th }}$ century by Manuel Severim de Faria. In view of the long interval that separates the publications, we seek to understand the events, contexts and circumstances that led to their

1. Universidad Federal Fluminense (Brasil); fernandoaltoe@yahoo.com.br

Maestro en Historia del Programa de Pós-Graduação em História de la Universidade Federal Fluminense, Río de Janeiro, Brasil. El artículo contó con la colaboración del profesor Rodrigo Bentes Monteiro, asesor de mi tesis de maestría «Da pluma à prensa. Trajetória documental e autoria nos panegíricos de João de Barros». Disponible en: https://www.historia.uff.br/stricto/td/2365. Igualmente, agradezco los comentarios de los profesores André de Melo Araújo, Iris Kantor y Federico Palomo. 
printing, as an expression of a cross work of several agents, as well as the series of events related to the production of their meanings as objects.

\section{Keywords}

João de Barros; Panegyric; Documentary trajectory; Manuscripts; Printed 


\section{INTRODUCCIÓN}

Numerosos estudios se han realizado sobre la vida y la obra de João de Barros (I496-I570), al menos desde el siglo XVII. Manuel Severim de Faria se ocupó de su primera biografía, publicada en i624. Después de este primer bosquejo biográfico, António Baião realizó otro estudio en profundidad, cuyos resultados se publicaron en la serie titulada «Documentos inéditos sobre João de Barros», en I9I7. También en el siglo XX salieron a la luz otros cuatro estudios biobibliográficos de autoría de António Alberto Banha de Andrade, Charles R. Boxer y António Borges Coelho².

La extensa obra de João de Barros puede dividirse en algunas corrientes de recepción. La primera de ellas se refiere a la expansión en el extranjero, y los estudios realizados en torno a este tema tienen en cuenta principalmente las Décadas da Ásiả. Otra corriente se orienta al idioma portugués y al ideal pedagógico, concentrándose en la Cartinha com os preceitos e mandamentos da santa madre igreja, en la Gramática da língua portuguesa, en el Diálogo em louvor da nossa linguagem, en el Diálogo da viciosa vergonha y en el Diálogo dos preceitos morais com prática deles em modo de jogo ${ }^{4}$. Una tercera línea trata de la polémica antijudía, con los textos centrales de Ropicapnefma y el Diálogo evangélico sobre os artigos de fé contra o Talmud dos judeus 5 .

Al igual que estos escritos de João de Barros, los panegíricos también han recibido la atención de los historiadores en las últimas décadas. El Panegírico de D. João III ha sido entendido como un vehículo de ideas de Erasmo $^{6}$ o bien como un portador de ideas de Maquiavelo en Portugal 7 . Para Joseph Klucas, Barros se habría acercado a Erasmo en su retrato del príncipe cristiano y en las virtudes atribuidas al rey D. João Ill. Por su parte, Martim de Albuquerque identifica las relaciones / conexiones entre los escritos de Maquiavelo y el Panegírico de D. João III, señalando que Barros no solo leyó, sino que también reprodujo pasajes de los Discorsi sopra la prima deca di Tito Livio (I53I) y otros tres textos publicados en I532: Il Principe, Istorie Fiorentine y Descrizione del modo tenuto dal Duca Valentino nello ammazzare Vitellozzo Vitelli, Oliverotto da Fermo, il Signor Pagolo e il duca di Gravina Orsini. Del examen intertextual realizado, Albuquerque concluye que Barros hizo una especie de "selección» de los escritos de Maquiavelo, con el uso de ejemplos insertados en una narrativa de naturaleza ética, moral y religiosa. Por otro lado, Giuseppe Marcocci sostiene que João de Barros acogió parte del vocabulario político del escritor florentino, como la utilidad de las fortalezas, las crisis abiertas en el imperio romano debido al uso

2. Andrade, 1980. Boxer, 1981. Coelho, 1992; 1997.

3. Albuquerque, 1991. Avelar, 2003. Biedermann, (2003). Cidade, 1968. Dias, 1969; 1986. Barreto, 1982; 1989. Laborinho, 1999. Matos, 1991. Rebelo, 1998. Révah, (1967). Saraiva e Lopes, 1996. Saraiva, 1972.

4. Almeida, (1959). Buescu, 1969. Castello-Branco, (1973). Cidade, (1950). Pichio, 1959. Pereira, 1955. RAMALHO, 1988.

5. Boxer, 1981. Coelho, 1996. Dias, 1969. Révah, 1950; 1975; 1983. En Brasil, la obra de João de Barros despierta el interés de los historiadores. En las disertaciones y tesis producidas, el foco de atención se centra en la Crônica do imperador Clarimundo, Ropicapnefma, en la Gramática da língua portuguesa, en los Diálogos Morais y en las Décadas da Ásia: Megiani, 1995. Conti, 2005. Vicente, 2008. HAHN, 2009. Mariguela, 2010. Panegassi, 2013. Reis, 2013. BEZZI, 2014. SOUZA, 2014.

6. KLUCAS, (1984).

7. Albuquerque, 2007. Marcoccl, 2012 [2011]. 
de milicias mercenarias, la idea de que el príncipe fuera amado o temido, y el juicio sobre la religión de los antiguos, reproduciendo especialmente el esquema de los Dircorsi, en los que la base de la sociedad romana se asentaba en el miedo y en la autoridad de la religión. Frente a esta lectura temprana de las obras de Maquiavelo, Marcocci sugiere, si realmente data de I533, que el Panegírico de D. João III constituye «a primeira confirmação da recepção de Maquiavel em Portugal»».

Sobre el Panegírico da infanta D. Maria, existe el estudio pionero de Carolina Michaelis de Vasconcelos ${ }^{9}$. En su biografía sobre la infanta portuguesa, la filóloga comenta el panegírico atribuido a João de Barros. Dedicó algunas páginas a definir el año de composición del texto en I555, aunque se equivocó antes de los descubrimientos documentales de Alexandre de Lucena e Vale y António de Oliveira ${ }^{\mathrm{IO}}$. Estos dos historiadores dataron la escritura del Panegírico da infanta D. Maria en años diferentes: Lucena e Vale en 1544, Oliveira en I545. Maria do Rosário Cruz ${ }^{\text {II }}$ también utiliza este panegírico como fuente lateral para hablar de la princesa portuguesa y lo atribuye no a João de Barros, sino al fraile Francisco Barreiros. Los estudios aquí citados constituyen las principales obras producidas sobre los panegíricos de João de Barros.

El Panegírico da infanta D. Maria fue impreso en Lisboa por Manuel Severim de Faria en I655. Una segunda edición fue publicada en I675 y fue impresa por Fr. Miguel Pacheco, junto a la biografía de la infanta. En I740, con la reedición de Notícias de Portugal, se imprimió por tercera vez dicho panegírico junto al Panegírico de D. João III, que en ese momento era publicado por primera vez. En I79I, Joaquim Francisco Monteiro publicó en conjunto ambos textos. La última edición fue hecha por Manuel Rodrigues Lapa y fue publicada en I943, por la Coleção de Clássicos Sá da Costa.

Los estudios producidos sobre el panegírico de Barros, mencionados anteriormente, se basaron en esa edición de Manuel Rodrigues Lapa. Las excepciones son Giuseppe Marcocci -que confrontó la edición de I943 con el manuscrito del Panegírico de D. João III depositado en la Biblioteca Nacional de Portugal (BNP)-, Carolina Michaelis de Vasconcelos y Maria do Rosário Cruz. Mientras que el estudio de Vasconcelos se publicó mucho antes de la edición realizada por Lapa en I902, el estudio de Cruz es el único, entre los realizados sobre el Panegírico da infanta D. Maria, que utiliza el manuscrito de ese texto depositado en el Arquivo Nacional de Torre do Tombo (ANTT).

El objetivo del presente estudio es seguir la trayectoria documental de estos dos panegíricos y analizar las circunstancias de sus publicaciones. Se trata de textos publicados mucho tiempo después de haber sido escritos, lo que amerita un examen cuidadoso del período comprendido entre su composición y su impresión. En su biografía sobre João de Barros, Manuel Severim de Faria no hizo mención sobre dichos escritos, aunque si comentó otros del autor, ya publicados en ese momento. Si el Panegírico da infanta D. Maria iba a ser impreso por el propio Severim de Faria

\footnotetext{
8. MARCOCCI, 2012: 136.

9. VASCONCELOS, 1983 [1902].

10. Lucena e Vale, 1970. Oliveira, (1992)

11. CRUZ, 1993.
} 
en I655 -cuyo testimonio sugiere que hasta ese momento ignoraba dicho texto- el Panegírico de D. João III siguió una trayectoria aún más larga, hasta ser finalmente publicado en I740. Estos textos sufrieron alteraciones en el curso de las copias manuales, lo que lleva a discutir acerca de su contenido escrito y de los diversos autores intelectuales involucrados, no solo la persona responsable de la composición original del texto, sino también los profesionales de la edición y la impresión.

\section{EL PANEGÍRICO DE D. JOÃO III}

\section{EL MANUSCRITO}

El Panegírico de D. João III fue publicado junto con la reedición de Notícias de Portugal, una obra escrita por Manuel Severim de Faria e impresa originalmente en I655. No hay información sobre el origen del manuscrito, aunque algunas referencias arrojan luz sobre su situación en el momento en que fue encontrado. Una de las referencias se encuentra en la sección titulada «Aos leitores», al comienzo de la segunda edición de Notícias de Portugal. Como es sabido, esta reedición de I740 fue realizada por José Barbosa. Las palabras de abajo son probablemente del «editor» Barbosa:

[...] E como o Elogio de João de Barros ao mesmo rei D. João III é obra em que se vê a grande erudição, e delicadíssimos pensamentos de um homem tão excelente, se imprime agora, ainda que com alguns erros, que senão puderam emendar na falta do original, e de cópia exatíssima; e como estes Elogios não tinham ordem, se lhes deu a que pedia a sua matéria ${ }^{12}$.

Este pasaje llama la atención sobre el precario estado del manuscrito al que se tuvo acceso y la intervención del «editor» sobre el texto consultado. A falta del manuscrito original o de una "copia exacta», José Barbosa intervino en el texto como le pareció oportuno. Si estos datos revelan cierta preocupación por el rigor erudito -lo que no es sorprendente, ya que el responsable de las adiciones a la obra de Severim de Faria era miembro de la Academia Real da História Portuguesa- el mismo pasaje indica el deseo de rehabilitar la memoria de alguien ilustre y que habría hecho mucho por glorificar la patria portuguesa en el pasado.

Otros dos testimonios provienen de los calificativos del Santo Oficio D. Caetano de Gouveia y D. António Caetano de Sousa, ambos miembros de la Academia Real da História. Al autorizar la publicación de esa nueva edición de las Noticias de Portugal, D. Caetano de Gouveia afirma: «Li as Notícias de Portugal de Manuel Severim de Faria com as adições, que de novo se lhe acrescentam, e com o excelente Panegírico, que o grande João de Barros fez ao rei D. João Ill e nenhuma coisa encontrei oposta à pureza da fé $[. ..] »^{13}$. D. António Caetano de Sousa también menciona el nombre de João de Barros y el nuevo panegírico en proceso de publicación:

12. FARIA, 1740: s/p.

13. Ibid. 
Esta obra [Notícias de Portugal], que agora se pretende juntamente reimprimir, se ia fazendo tão rara, que dificultosamente poderia chegar às mãos daqueles que se aplicam com curiosidade a ler, assim é de louvar o zelo de novo se imprimir com adições, que a fazem mais estimável por serem notícias, que instruem, e põem a obra depois de quase um século no nosso tempo. No fim se lhe ajunta aquele célebre Panegírico feito no ano de 1533 ao rei D. João III por aquele insigne varão o grande João de Barros, cujo nome é o maior Elogio, para a recomendação da obra» $\aleph^{14}$.

El nombre de João de Barros ayudó para dar aún más valor a las Notícias de Portugal y dar a la obra una buena reputación. En su época, el humanista ocupó importantes cargos dentro de la administración portuguesa y escribió un expresivo conjunto de textos. Contribuyó a «ilustrar a pátria e deixar de seus naturais gloriosa memória», como ya había registrado Manuel Severim de Faria en su biografía dedicada al letrado portugués ${ }^{15}$. Publicar uno de sus textos, hasta entonces olvidado, significaba no sólo rehabilitar su figura, sino traer al presente la memoria de un glorioso pasado histórico, en sintonía con las aspiraciones de la Academia Real da História.

Si se desconoce el origen del manuscrito, es plausible pensar que el texto tuvo poca o ninguna circulación y solo fue descubierto en el siglo XVIII. Esta hipótesis se debe a que, en I624, al escribir y publicar la primera biografía de João de Barros, Manuel Severim de Faria no hizo mención alguna a los supuestos panegíricos escritos por ese letrado, aunque sí habló de las demás obras del autor publicadas hasta entonces. Al imprimir sus Notícias de Portugal en I655, Faria incluyó en ese texto el Panegírico da infanta D. Maria, lo que no ocurrió con el Panegírico de D. João III, probablemente porque este panegírico permaneció desconocido para Severim y el público en general. Es posible que el manuscrito haya sido descubierto por miembros de la Academia Real da História como parte de los esfuerzos para inventariar y catalogar las bibliotecas y archivos del reino. Una vez encontrado, fue incluido en la reedición de Notícias de Portugal, obra que ya trajo otro panegírico de Barros.

\section{LA EDICIÓN}

Según Roger Chartier, los autores no escriben libros, sino textos, porque los libros se producen a partir del trabajo de innumerables agentes como editores, impresores y libreros. Si por un lado hay que considerar las estrategias textuales y las intenciones del autor, por otro lado, no se pueden perder de vista las decisiones de los editores y las limitaciones impuestas por los talleres de imprenta ${ }^{16}$. En el frontispicio de las Notícias de Portugal y en la dedicatoria, se puede ver que la reedición de las Notícias fue iniciativa del librero Manoel da Conceição. El período de su actividad en Portugal duró 25 años, como indica el estudio realizado por Diogo Ramada Curto ${ }^{17}$.

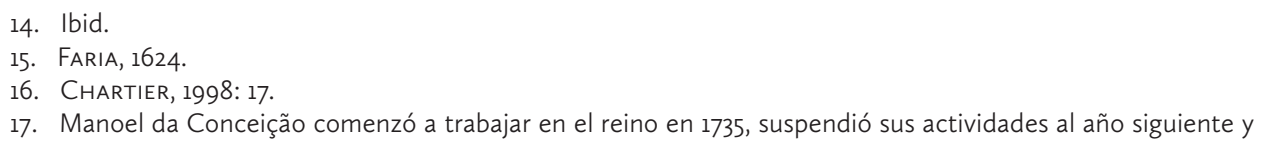


La dedicación está dirigida a José Caldeira, sacerdote del hábito de San Pedro ${ }^{\text {I8 }}$. En la dedicatoria, el librero Manoel da Conceição destaca las cualidades intelectuales de su protector, subrayando que solo la sabiduría y el cultivo de las letras podían hacer posible el patrocinio de esa empresa. Y concluye que no es justo que la memoria de Manuel Severim de Faria «ficasse exposta aos perigos, que podia achar na grossaria, de quem não conhece a estimação, que lhe é devida $»^{19}$. A pesar de demostrar el deseo de rehabilitar la obra de un hombre distinguido como Manuel Severim de Faria, el interés comercial también llevó a las acciones del librero Manoel da Conceição. Como librero interesado en hacer una obra vendible, Manoel da Conceição se movió por intereses económicos cuando reeditó Notícias de Portugal.

Entre los libreros portugueses del siglo XVIII, era una práctica común anunciar la venta de libros en la Gazeta de Lisboa. Según el estudio de André Belo, hubo un crecimiento de la difusión de las obras impresas y del carácter no especializado de la literatura anunciada, ya que se dirigía a un mercado estrecho y en formación. Estos anuncios acompañaron a la publicación de la Gazeta desde su inicio y tuvieron un espacio definido en la revista: en la última página, bajo el título «advertencias» o simplemente separado del resto de las noticias por un filete, se anunciaban en cursiva las obras publicadas o en vías de publicación en el momento en que la Gazeta salía a la luz. Entre I7I5 y I760, se anunciaron unos 2.500 títulos de obras impresas ${ }^{20}$.

A partir de la consulta de estos anuncios, durante el período en que Manoel da Conceição estuvo activo en Lisboa, se identificaron I2O anuncios de libros a lo largo de 25 años ${ }^{21}$. El número supera la contabilidad realizada por André Belo en relación con otros libreros que también utilizaron la revista periódicamente, como Bento Soares (con 90 títulos anunciados entre 1723 y I759) y João Rodrigues (con 80 títulos anunciados entre I721 y 1758). Los anuncios de Manoel da Conceição no superaron en cantidad a los de Manuel y Guilherme Diniz, los vendedores de gacetas: entre I7I5 y I752, anunciaron unos I50 títulos, entre libros y folletos ${ }^{22}$. En los anuncios

volvió a vender libros en 1737, trabajando hasta 1751. Reanudó sus actividades en 1753, y también trabajó entre 1755 y 1759 y en 1761,1762 y 1767. Vendía libros en su tienda de la Rua Direita do Loreto, junto al Conde de Santiago hasta el terremoto de 1755. Después del terremoto, aparece en la Rua Direita da Boa Esperança, junto al Poço dos Negros. CURTO, 2007: 146.

18. Diogo Barbosa Machado presenta una breve biografía del presbítero Caldeira (nacido en Lisboa en 1701) e informa sobre sus tres libros religiosos publicados. MACHADO, 1747, vol. II: 836-837. Aunque no era un autor de prestigio, sería alguien con suficientes recursos para patrocinar la publicación de Notícias de Portugal.

19. FARIA, 1740: s/p.

20. Belo, 2001. Según Belo, los vendedores utilizaban la Gazeta de Lisboa para anunciar las novedades editoriales $y$, a veces, otros títulos a la venta en su tienda. El anuncio fue utilizado principalmente por quienes no tenían otros medios para anunciar sus ventas, como las pequeñas librerías e imprentas de Lisboa y los autores de libros que trataban de agotar sus ejemplares y obtener así el pago de sus obras.

21. En cuanto al período de actividad de Manoel da Conceição en Portugal, seguimos los datos presentados por Diogo Ramada Curto, entre 1735 y 1767. El librero no actuó en todos estos años. Sólo utilizamos las publicaciones periódicas correspondientes a los años en que Conceição trabajó en Portugal, consultando la versión digitalizada de los boletines disponibles en el sitio: http://hemerotecadigital.cm-lisboa.pt/Periodicos/GazetadeLisboa/ GazetadeLisboa.htm. Faltan las gacetas de los años 1753 y 1755 de la colección de la Hemeroteca Municipal de Lisboa. En 1762, los boletines sólo se publicaron en el primer semestre, siendo suspendidos entre el 16 de junio de 1762 y el 3 de agosto de 1778 .

22. BELO, 2001: 87-88. Belo no contabilizó los anuncios de Manoel da Conceição, limitándose a unas pocas librerías e imprentas de Lisboa, y reconoce que no ha hecho una contabilidad sistemática que incluyera a todas las librerías e imprentas indicadas en los anuncios. 
de Conceição, cabe mencionar las obras cuyos autores pertenecían a los cuadros de la Academia Real da História.

Autores de renombre como Francisco Xavier de Meneses ( $4^{\circ}$ Conde de Ericeira) y los teatinos Caetano de Gouveia, António Caetano de Sousa y Jerónimo Contador de Argote hicieron anunciar sus obras en la Gazeta de Lisboa y las vendieron en la tienda de Manoel da Conceição. Entre los miembros de la Academia Real da História, el autor que más destaca por el número de obras anunciadas es el teatino José Barbosa. Durante el período considerado, Barbosa tuvo ocho obras publicadas: cuatro sermones, dos alabanzas, un epítome y una oración. Con motivo de la muerte del clérigo, Manoel da Conceição apeló a la Gazeta para anunciar el Elogio fúnebre do reverendíssimo P. D. José Barbosa..., compuesto y recitado en la Academia el iz de agosto de I75I por el Conde de Vila Maior, Manoel Teles da Silva ${ }^{23}$.

Estos datos revelan una proximidad del librero Manoel da Conceição con los miembros de la Academia Real da História, en particular con José Barbosa, y pueden explicar por qué este último fue el responsable de las actualizaciones de las Notícias de Portugal. Como era de esperar, en el número 22 de la Gazeta, el 2 de junio de I740, se anuncia la publicación de las Notícias de Portugal, con la siguiente descripción: «Imprimiram-se segunda vez in folio as Notícias de Portugal escritas por Manoel Severim de Faria acrescentadas nesta segunda impressão pelo Padre D. José Barbosa Clérigo Regular da Divina Providência com um Elogio a ElRey D. João III por João de Barros» ${ }^{24}$. En el anuncio podemos ver la referencia al nombre de José Barbosa y el nuevo panegírico de João de Barros, que acompañaba a esa edición. Ambas pueden indicar la estrategia utilizada por el librero para atraer la atención del público, por la reputación que el nombre de Barbosa confirió a la obra o por la buena acogida del género panegírico entre los lectores. $\mathrm{Al}$ año siguiente, se hizo otro anuncio en relación con la venta de Notícias de Portugal, como una forma de recordarle al público esa obra:

Imprimiu-se a vida do venerável Padre Bartholomeu do Quental, fundador da Congregação do Oratório no Reino de Portugal. Vende-se na loja de Manoel da Conceição, livreiro na rua direita do Loreto, onde se achará também o livro intitulado Notícias de Portugal, escritas por Manoel Severim de Faria e adicionadas pelo Reverendo P. D. José Barbosa²5.

Esta vez se omitió la referencia al panegírico de Barros, pero se conservó la de D. José Barbosa, seguramente porque su nombre daba peso y reputación a la obra ${ }^{26}$.

D. José Barbosa (1674-I750) fue, en su época, un erudito de enorme proyección. Era el mayor de los hermanos Barbosas (nos referimos a Inácio y Diogo Barbosa Machado). Abrazó la religión de los teatinos cuando aún era joven, dándose a

23. Gazeta de Lisboa, $n^{\circ} 51,21$ de diciembre de 1751. La obra se anuncia nuevamente en el Suplemento à Gazeta de Lisboa, $\mathrm{n}^{\circ} 52$, del 1 de enero de 1752.

24. Gazeta de Lisboa, $\mathrm{n}^{\circ} 22,2$ de junio de 1740.

25. Gazeta de Lisboa, $\mathrm{n}^{\circ} 30,27$ de julio de 1741 .

26. La relación entre el librero Manoel da Conceição y el académico Barbosa expresa el vínculo entre la Gazeta de Lisboa y la Academia Real de História, como muestra André Belo en su estudio. Entre 1721 y 1726 la imprenta de la Gazeta fue también la de la Academia. La Gazeta también difundió noticias del mundo académico en general y de las actividades de academias más pequeñas, de Lisboa o de la provincia. BELO, 2001. 
conocer como orador. En Portugal, los teatinos siempre tuvieron buenas relaciones con la nobleza y la casa real, ya sea por la constante reafirmación de los valores religiosos, o por el alto nivel cultural que trataron de mantener entre ellos. Entre los portugueses, algunos de los nombres más importantes de la cultura erudita del siglo XVIII también procedían de esa orden, como Rafael Bluteau, Manuel Caetano de Sousa, António Caetano de Sousa, Jerónimo Contador de Argote y Tomás Caetano

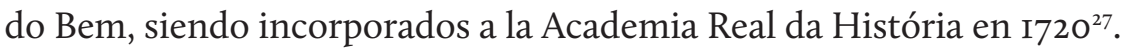

Desde I7I3 José Barbosa fue el cronista de la casa de Braganza. En la Academia se le encargó componer las Memórias históricas del Conde D. Henrique y su hijo. A lo largo de su vida, escribió y publicó epítomes, panegíricos, alabanzas y sermones, de los que su hermano Diogo Barbosa Machado da noticias detalladas ${ }^{28}$. Su escrito más conocido sería el Catálogo cronológico, histórico, genealógico e crítico das rainhas de Portugal e de seus filhos. La obra, publicada en I727, sería la primera en la historiografía portuguesa en colocar a las reinas en el centro de estudio. José Barbosa también vinculó su nombre a la reedición de los Elogios dos reis de Portugal, de fraile Bernardo de Brito con detalles adicionales al texto. Así, el académico escribió los elogios referentes a Felipe IIl y Felipe IV, y los alusivos a los primeros monarcas de Braganza, D. João IV, D. Afonso VI, D. Pedro Il y D. João V (monarca reinante). Incluso viviendo un siglo después de Brito, Barbosa trató de imitar su estilo y respetar el plan general de la obra, tratando de preservar el espíritu histórico que guio la realización de los Elogios -aunque no hay ningún prólogo o advertencia de su organizador. Solo hay la dedicatoria al príncipe D. José (más tarde rey) y la epístola al secretario de Estado Diogo de Mendonça Corte Real -ambas escritas por Manuel Lopes Ferreira, propietario de la Oficina Ferreiriana-, lo que lleva a Serrão a concluir que la edición fue encargada a Barbosa para satisfacer las ventajas editoriales $^{29}$. Como se verá más adelante, el caso no difiere de la forma en que se llevó a cabo la reedición de Notícias de Portugal.

La reimpresión de las Notícias de Portugal fue hecha por António Isidoro da Fonseca, que trabajó en Portugal como impresor y librero entre 1728 y $1747^{30}$. Aunque hay poca información sobre su vida, el impresor alcanzó cierto éxito en su oficio, debido a las numerosas obras que salieron de su taller de tipografía. Los imprimió hasta por lo menos I745, aunque sin contar con un privilegio de impresión, importante en el ambiente de la imprenta portuguesa. De las obras más conocidas que salieron de su taller es el primer volumen de la Bibliotheca lusitana, cuyo autor, Diogo Barbosa Machado, lo hizo imprimir en I74I. En I746, la Inquisición requirió que todos los impresores de la corte firmaran un término de compromiso, por el cual se comprometían a no imprimir sin las licencias apropiadas del Santo Oficio. El término no fue firmado por Isidoro da Fonseca, lo que indica que en ese momento ya no dirigía un taller en el reino. El impresor se instaló entonces en Río de Janeiro, donde dirigió su llamado «segundo» taller desde i747. En Brasil produjo al menos

27. GOUVEIA, 2001: 271-274.

28. Para la biografía del autor y la lista de sus obras, véase MACHADO, vol. II: 825-829.

29. SERRÃo, 1974: 123-128.

30. CURTO, 2007: 69 
algunos panfletos, tesis jesuíticas y un libro de compromiso de hermandad religiosa hasta que se vio obligado a regresar a Portugal en I749. En el reino, pidió al Conselho Ultramarino permiso para reanudar sus actividades en Rio de Janeiro, que le fue denegado en $1750^{31}$.

En el estudio de Jair Norberto Rattner sobre las obras impresas por António Isidoro da Fonseca depositadas en la Biblioteca Nacional de Portugal, se puede observar la conexión del impresor con algunos miembros de la Academia Real da História. De los teatinos, Isidoro imprimió obras de Jerónimo Contador de Argote (dos), Tomás Caetano do Bem (dos), Caetano de Gouveia (tres), António Caetano de Sousa (dos) y José Barbosa (veinte). Entre estos, José Barbosa tuvo el mayor número de obras impresas por ese tipógrafo. Aunque el estudio de Rattner no abarca todas las obras impresas por Fonseca, sino sólo las disponibles en la BNP (II5 obras publicadas entre I735 y I748), los números presentados revelan una conexión entre el impresor y los teatinos, en particular José Barbosa. Los datos también indican una relación entre Isidoro y el librero Manoel da Conceição: en al menos siete obras, el nombre Conceição aparece como el librero responsable de sus ventas ${ }^{32}$. Por lo tanto, también hay una conexión entre el librero y el impresor Isidoro da Fonseca, y de este con José Barbosa.

Como ocurre con los Elogios dos reis de Portugal de Bernardo de Brito, la reedición de las Notícias de Portugal también estuvo a cargo de José Barbosa, quien actualizó la obra escrita por Manuel Severim de Faria. Si comparamos las dos ediciones de las Notícias, de I655 y I740, las intervenciones en la segunda son evidentes. El editor intervino en el texto en varias ocasiones, con adiciones y actualizaciones.

Barbosa agrupó los materiales en un voluminoso folio y se preocupó de preservar la forma y el contenido de la edición de i655. En cuanto a los aspectos formales, mantuvo la puntuación, la ortografía, las citas en latín y también las ilustraciones de las monedas que acompañan al texto. En cuanto al contenido, las intervenciones son visibles desde el principio de la obra, cuando el editor presenta una breve biografía de Manuel Severim de Faria. En el discurso IV, sobre las monedas nacionales, continuó el inventario iniciado por Severim de Faria, presentando las monedas de los reinados de D. Afonso Vl, D. Pedro Il y D. João V. En la sección «Memória de alguns cardeais portugueses», añadió las biografías de los cardenales de finales del siglo XVII y de la primera mitad del XVIII, a saber, Veríssimo de Lancastre, Luís de Sousa, Nuno da Cunha Ataíde, José Pereira de Lacerda, João da Motta e Silva y Tomás de Almeida. Al final de esta sección, aparece escrito de su propio puño el nombre de otros seis cardenales, ciertamente prelados portugueses de la época ${ }^{33}$.

31. Sobre el período de actividad de António Isidoro da Fonseca en Río de Janeiro, véase el estudio desarrollado por Jerônimo Duque Estrada de Barros: Barros, (2012).

32. RATTNER, 1990. Un estudio más detallado fue realizado por Jerônimo Duque Estrada de Barros, quien actualizó el estudio realizado por Rattner, localizando otras obras impresas por Isidoro da Fonseca en Brasil, Portugal y otras colecciones alrededor del mundo (BARROS, 2012): artículo publicado en línea en el sitio web de la Fundação Biblioteca Nacional (Rio de Janeiro), 2012. Consultado el 2 de febrero de 2019. URL: https://www.bn.gov.br/en/ node/1936.

33. El ejercicio de comparación entre las dos ediciones se encuentra también en Francisco Innocencio da Silva: SiLVA, 1962: 107-108. Francisco Lourenço Vaz llama la atención sobre el concepto del libro de la época, en el que 
En la sección dedicada a los elogios, la edición de I655 trae, en ese orden, el Elogio de Bernardo de Brito, el Elogio de Évora, el Elogio do rei D. João de Portugal III do nome, de António de Castilho, y el Panegírico a mui alta e esclarecida princesa infanta D. Maria nossa senhora, de João de Barros. En la edición de I740, la gran novedad editorial se presenta bajo el título: Ao muito alto e muito poderoso rei de Portugal D. João III deste nome. Panegírico de João de Barros. Los otros cumplidos se transcriben a continuación de este nuevo panegírico de Barros, que en ese momento era_publicado por primera vez.

Como hemos visto, el Panegírico de D. João III fue presentado en esta nueva edición como una gran novedad editorial. Una de las referencias al texto se encuentra en la sección «Aos leitores», otras dos se hacen también en la propia obra, por los calificadores del Santo Oficio y una cuarta en el anuncio de la Gazeta de Lisboa. La novedad del texto y su importancia histórica contribuyeron a dar un valor singular a la reedición de las Notícias de Portugal, como otro episodio importante de la historia secular del reino, si bien los fabulosos panegíricos fueron a veces desacreditados en esa época. En la dedicatoria a la traducción del Sermão que pregou em dia de santa Luzia o cardeal Cassini, una obra impresa en I739, Caetano de Gouveia Pacheco habría escrito: «Os panegíricos [...] passam hoje por documentos de pouca fé. Deixem vossas excelências os seus louvores por conta da história, porque só ela, sem lhe serem necessárias as cores da eloquência, os saberá retratar com toda a perfeição» ${ }^{34}$. Si es cierto que los panegíricos empiezan a sufrir un descrédito en los círculos académicos del siglo XVIII, el público lector más amplio no debería compartir el mismo sentido crítico. Según Isabel Ferreira da Mota, los panegíricos eran vendibles y bien aceptados entre los lectores, así como los discursos y las obras de la historia, sobre todo si llevaban el sello de la Academia Real da História Portuguesa ${ }^{35}$.

Sin embargo, el Panegírico de D. João III se imprimía por primera vez: era un documento raro, depositado en algún archivo y cuya existencia era desconocida, ya que el propio Severim de Faria, en una biografía dedicada a João de Barros en el siglo anterior, no hacía mención alguna de este texto. En el esfuerzo realizado por los miembros de la Academia Real da História Portuguesa para inventariar los archivos del reino y reunir tantos documentos como fuera posible, se publicaron muchos manuscritos previamente desconocidos. Aún, de acuerdo con Ferreira da Mota, los teatinos, entre los que se encontraba José Barbosa, constituyeron un grupo que llevó a cabo un elaborado y estructurado trabajo de erudición y crítica, cuyas marcas estaban en la búsqueda de fuentes, en la crítica bibliográfica y en el rigor de la escritura. Su librería era muy rica en libros raros, manuscritos antiguos, medallas, grabados y colecciones de documentos, que los clérigos adquirieron a lo largo de los años con la ayuda financiera de la corona ${ }^{36}$.

\footnotetext{
«completar e acrescentar um original eram objetivos presentes nas reedições e [...] transmit[iam] a ideia de tentar fixar ou sistematizar os fatos e conhecimentos entretanto ocorridos» (VAZ, 2003).

34. Véase el pasaje en António Coimbra Martins (MARTINS, 1984: 843) y Luís de Souza Rebelo (Rebelo, 1982: 137). En estas obras, los autores discuten los signos de declive de los panegíricos en el avance del siglo XVIII.

35. MOTA, 2003: 86

36. Ibid: $68-70$
} 
José Barbosa fue también lector y admirador de la obra de João de Barros, como lo atestigua Tomás Caetano do Bem en la biografía dedicada a su compañero de orden. Según el autor teatino, José Barbosa era un excelente orador, hablando su lengua materna con propiedad y pureza, cuidando de evitar su corrupción. Aunque entendía el castellano, el francés y el italiano, sólo usaba estos idiomas para la erudición. En las composiciones que dejó registradas en portugués, no hay términos en idiomas extranjeros. Y continúa Tomás Caetano do Bem:

Esta abundância e pureza de vozes adquiriu o padre Barbosa na contínua lição e grande reflexão, com que lia as obras de Barros, Lucena, Vieira, e outros; e principalmente de Jacinto Freire de Andrade, na vida de D. João de Castro, cuja obra leu vinte e oito vezes, porque no seu conceito e no de todos os mais inteligentes é este escritor um dos primeiros mestres da eloquência portuguesa ${ }^{37}$.

João de Barros era para José Barbosa una autoridad intelectual, cuyo nombre era digno de ser recordado dadas las inestimables contribuciones que legó a la posteridad, en particular, en el ámbito lingüístico. De João de Barros es la segunda gramática de la lengua portuguesa, obra en la que el autor realiza un gran trabajo de normalización y reflexión sobre la lengua materna. Imprimir uno de sus manuscritos hasta entonces desconocido, era para José Barbosa -cultor de la lengua portuguesa- una forma de rehabilitar la memoria de alguien que contribuyó enormemente en el pasado a elevar la dignidad de la lengua vernácula portuguesa.

No se sabe nada del Panegírico de D. João III antes de su publicación, ni cómo fue encontrado. La única información sobre el texto se encuentra en la sección «Aos leitores» de las Notícias de Portugal, probablemente escrita por José Barbosa ${ }^{38}$. Aunque hay pocas palabras, el extracto tiene algunas implicaciones: Barbosa afirma que imprimió el panegírico con «algunos errores», ya que no ha encontrado otra fuente más fiable que pudiera darle una imagen más precisa del texto originalmente compuesto. Estas preocupaciones ilustran el perfil de los miembros de la Academia Real da História Portuguesa, para quienes el rigor documental era la regla fundamental ${ }^{39}$. Está claro, según sus palabras, que José Barbosa no tuvo acceso a un texto terminado, bien ordenado y estructurado. Al contrario, se encontró con fragmentos, podemos decir, al azar y sin ningún orden. Por eso procedió a su manera.

El único manuscrito del Panegírico de D. João III que se conoce está bajo la custodia de la BNP. Cuando consultamos el texto de una copia escaneada, es evidente que no pudo ser el que menciona Barbosa, ya que el documento no presenta las características descritas por el editor. Es un texto de 78 páginas escritas y numeradas por ambas caras, con una ortografía regular gracias al trabajo de un solo copista, y está bien ordenado. No se trata de un texto fragmentado, como indica el Padre

37. BEM, 1794, tomo II: 170 .

38. «[...] E como o Elogio de João de Barros ao mesmo rei D. João III é obra em que se vê a grande erudição, e delicadíssimos pensamentos de um homem tão excelente, se imprime agora, ainda que com alguns erros, que senão puderam emendar na falta do original, e de cópia exatíssima; e como estes Elogios não tinham ordem, se lhes deu a que pedia a sua matéria». Faria, 1740: s/p.

39. МотА, 2003: 70 . 
José Barbosa, sino de un documento que configura una unidad. Todo esto nos lleva a pensar en las siguientes hipótesis:

- Si el manuscrito depositado en la BNP ya existía antes de la edición de I740, lo más probable es que José Barbosa no lo consultara. Sus palabras no apuntan a $\mathrm{eso}^{40}$;

- Si el manuscrito de la BNP ya existía antes de la edición de I740 y José Barbosa no lo consultó, la edición que realizó se mantuvo prácticamente idéntica al manuscrito, lo que es una gran coincidencia;

- Si este manuscrito y la edición de I740 son muy similares y José Barbosa no consultó esa fuente, es posible que haya sido copiado más tarde de la edición realizada por Barbosa;

- O, como último caso a considerar, y que nos parece más evidente, si el manuscrito depositado hoy en la BNP y la edición de $\mathrm{I} 740$ son prácticamente idénticos, ese manuscrito puede haber salido de las manos del propio José Barbosa o de un copista, habiendo sido preparado sobre la base de los papeles que dice haber encontrado, y ese fue el manuscrito que sirvió de base al impresor.

A partir del análisis del documento ${ }^{41}$, identificamos las siguientes características. El título del manuscrito que se muestra en la portada es Ao mui alto e muito poderosõ Rey de Portugal D. João 3o. deste nome. Panegirico de João de Barros. Aparentemente, ese título fue diseñado. A su lado hay un ex-libris de la Biblioteca Real. En el reverso del folio que lleva el título comienza el texto, dispuesto en dos columnas. A lo largo de 78 folios, sólo hay dos párrafos individuales. El documento presenta una escritura elegante, pausada, ligera y con pocas conexiones, es decir, la mayoría de las letras son independientes y no se lanzaron en un solo hilo o en un movimiento continuo, como son las cursivas aligeradas. Probablemente situada entre los siglos XVIl y XVIII, la escritura puede ser clasificada como una cursiva humanística, hecha por un scriptor con un buen dominio del arte de la escritura ${ }^{42}$.

El documento tiene un espaciado en sus márgenes laterales y numerosas notas, lo que indica que el cuerpo del texto fue preparado para recibir las notas marginales.

40. Giuseppe Marcocci afirma que se trata de un manuscrito de principios del siglo XVII, aunque no presenta las pruebas que lo llevaron a tal conclusión: «Data dos inícios de Seiscentos uma alegada versão manuscrita do texto, a única encontrada até hoje. Não se sabe quando é que o códice, manifestamente manuseado (talvez na época da edição setecentista), tenha entrado na biblioteca régia». MARCOCCI, 2012: 254.

41. Cabe señalar una vez más que se ha accedido al texto a partir de una copia escaneada y se reconocen las limitaciones impuestas por el no contacto con su materialidad.

42. El trabajo de análisis documental y paleográfico contó con la asistencia de Alícia Duhá Lose, paleógrafa y profesora del Instituto de Letras de la Universidade Federal da Bahia (UFBa) y de Márcia Almada, profesora de la Escola de Belas Artes de la Universidade Federal de Minas Gerais (UFMG). 


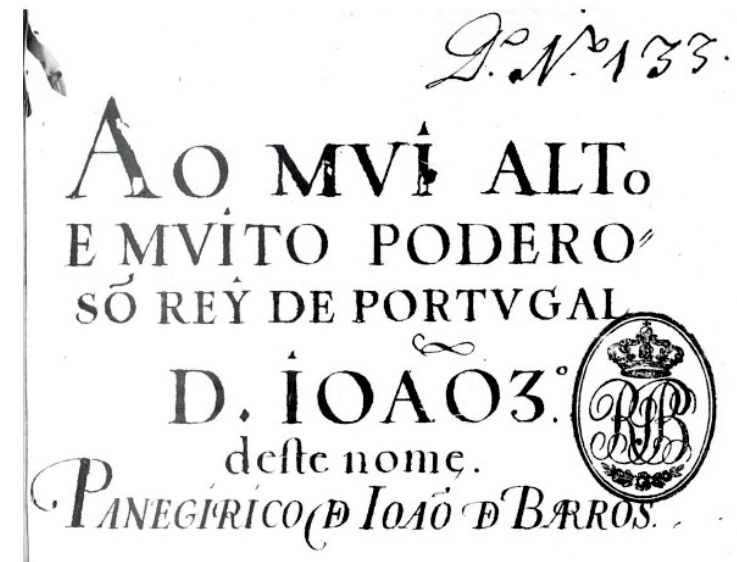

FIGURA 1. PORTADA DEL PANEGÍRICO. LISBOA, BNP, CÓDICE 3.060, PRIMERA IMAGEN DE LA COPIA DIGITAL. CONSULTADO MEDIANTE MICROFILMACIÓN

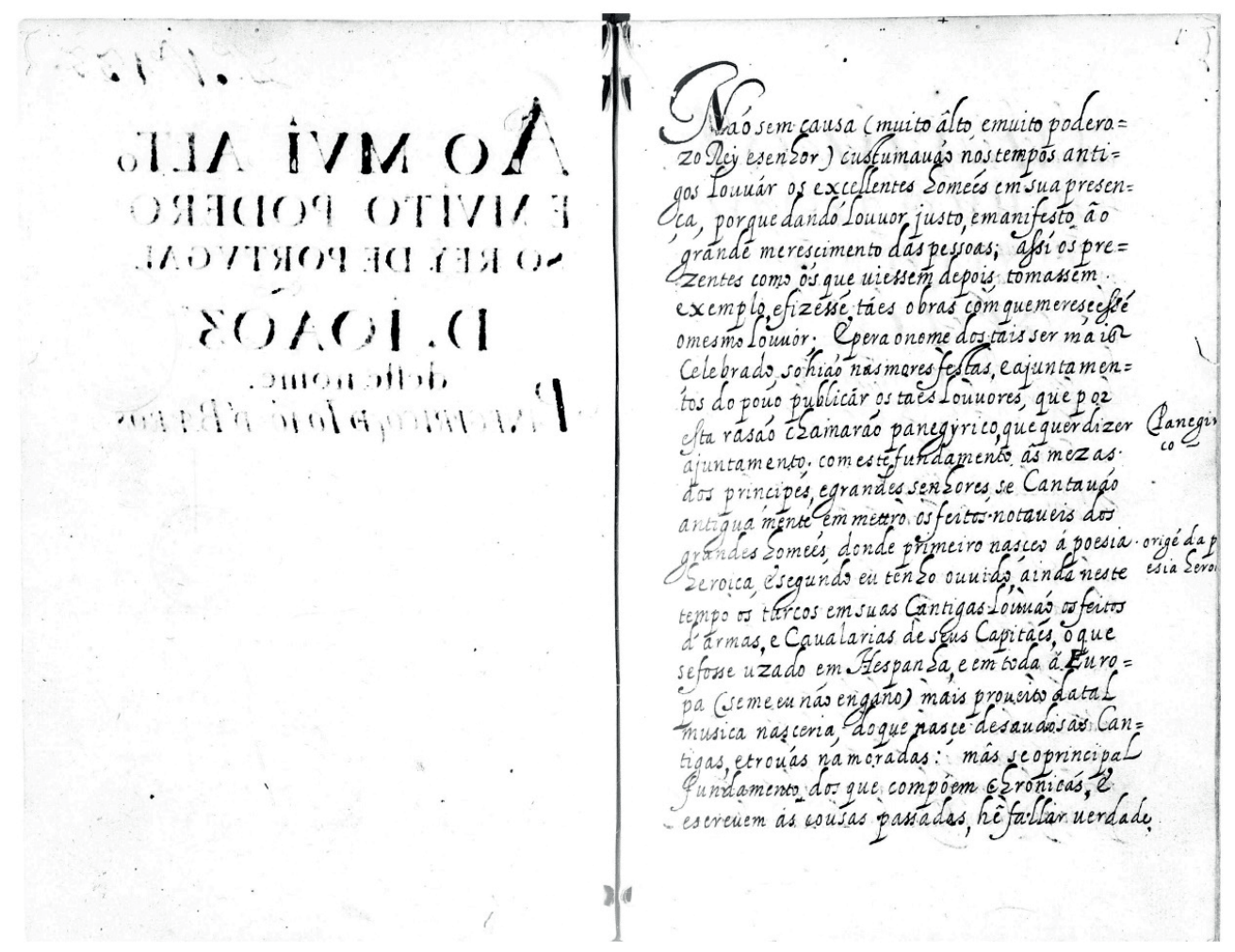

FIGURA 2. TEXTO INICIAL DEL PANEGÍRICO. LISBOA, BNP, Códice 3.060, SEGUNDA IMAGEN DE LA COPIA DIGITAL. CONSULTADO MEDIANTE MICROFILMACIÓN 
Se encontraron al menos diez borrones ${ }^{43}$ y cuatro pasajes subrayados ${ }^{44}$. Al final del texto, posiblemente haya una nota de posesión: «Antonio Moreira de Souza»45.

La edición impresa contiene el mismo título que el manuscrito de la BNP. La única diferencia en esta parte es que lleva el año de composición (I533) justo debajo del título, mientras que en el manuscrito de la BNP el año de composición aparece sólo al final del texto. A diferencia de este manuscrito, que contiene sólo dos párrafos, el texto impreso está organizado en I28 párrafos. Cuando se comparan, los dos textos no presentan tantas diferencias entre ellos, sólo algunos errores y variantes. El responsable de la edición contemporánea del panegírico, Manuel Rodrigues Lapa, señaló que las variantes que se encuentran en las ediciones impresas pueden ser legítimas, siendo obra del propio autor ${ }^{46}$. Por citar dos ejemplos, en la mayoría de los casos estos cambios se producen porque la persona responsable del texto impreso ha cambiado el orden de las palabras de una frase: donde «de mim verdadeiramente digo» ${ }^{47} \mathrm{y}$ «de poderosos reis» ${ }^{48}$ se leen en el manuscrito de la BNP, «de mim digo verdadeiramente $»^{49} \mathrm{y}$ «de reis poderosos $»^{50}$ se leen en el texto impreso. Hay un sinnúmero de otros casos similares. Observamos únicamente un gran corte (no sabemos si es deliberado o no) entre las dos versiones. Se trata de la supresión de 14 líneas en el texto impreso, no editadas del manuscrito ${ }^{5 \mathrm{I}}$. Aparte de eso, el texto es casi idéntico: incluso los paréntesis que se encuentran en todo el manuscrito se reproducen en el texto impreso. Por último, cabe señalar que la edición impresa de 1740 suprimió todas las notas marginales del manuscrito.

En vista del ejercicio de comparación, se supone que el texto manuscrito depositado en la BNP sirvió de modelo para la edición impresa de I740, o que esta impresión fue la base de la copia manuscrita existente. Nuestra hipótesis es que este manuscrito fue preparado por José Barbosa y un copista a su servicio, basándose en los papeles que el primero afirma haber encontrado. Así, este fue el texto que sirvió de base para la imprenta.

Aun en el siglo XVIII, tanto las Notícias de Portugal como el Panegírico de D. João III tenían una nueva edición. En I79I, las Notícias fueron reeditadas y ampliadas por Joaquim Francisco Monteiro. El editor agrupó los artículos en dos volúmenes, actualizó la ortografía y la puntuación y procedió a la actualización de la obra,

43. Las borraduras del manuscrito se encuentran en las páginas 9, 11, 41, 48, 54, 110, 131, 132, 143 y 150 . En algunos casos, se producen porque el copista cometió algún error al escribir una palabra. En otros, el borrado se produce a partir de la mancha de tinta.

44. Los extractos del manuscrito son los siguientes: «[...] no povo dos judeus não se acharia nenhum profeta, nem sacerdote que faltasse verdade, e que os judeus seriam lançados por todo o mundo [...]» (p. 46). «[...] sacrificar porcos [...] carne de porco [...] a circuncisão» [...]. (p. 49). «Mal se pode conservar o reino, em que os vassalos hão medo ao príncipe e não the querem bem [...]» (p. 54). «[...] com perigo que desistir dela com vergonha [...]» (p. 114).

45. La referencia a la supuesta nota de propiedad está en Marcocci (2012: 254, nota 551). Diogo Barbosa Machado informa que Antonio Moreira de Sousa nació en Lisboa el 13 de febrero de 1695, fue caballero de la Orden de Cristo, estudió filosofía en el colegio de los jesuitas y durante toda su vida reunió una selecta librería de impresos y manuscritos (Machado, 1741: 48-49).

46. LAPA, 1943: XXI.

47. Panegírico... (manuscrito), p. 28.

48. Panegírico... (manuscrito), p. 32.

49. Véase edición impresa, Notícias de Portugal, p. 305

50. Véase edición impresa, Notícias de Portugal, p. 308.

51. Panegírico... (manuscrito) p. 150. El extracto omitido de la edición impresa estaría entre las páginas 378 y 379. 
completando el cuadro de las monedas nacionales hasta el reinado de D. María I y las biografías de los cardenales portugueses. Pero algo llama la atención en esta nueva edición: el desmembramiento de la obra por el editor. Monteiro ordenó las Notícias en dos volúmenes in-oitavo y, en un tercer volumen, también in-oitavo, agrupó los elogios que acompañaron al resto de la obra, en el siguiente orden: Panegírico de João de Barros ao rei D. João III; Panegírico do mesmo autor à senhora princesa, infanta D. Maria; Elogio de António de Castilho ao rei D. João III; Elogio do doutor fr. Bernardo de Brito; Elogio de Évora. Como título, este tercer volumen presenta: Panegyricos do grande João de Barros. Fielmente reimpressos conforme sua antiga Linguagem $=$ ano de $1533^{52}$.

Es posible que el editor se haya visto impulsado por cierto oportunismo al decidir transformar la obra original in-folio y en un solo volumen en tres volúmenes in-oitavo. El nuevo formato indica la portabilidad y daría a los lectores una mayor facilidad de lectura. La nueva edición también sería más accesible comercialmente para el público. Inocêncio Francisco da Silva informa que el precio de los ejemplares de la segunda edición de las Notícias (I740) habría variado entre i:200 y i:60o reis ${ }^{53}$. El volumen de la edición de I79I, que contiene los panegíricos, informa, justo debajo del índice, que la obra fue gravada en 400 reis. Los otros volúmenes, aunque no traen el precio fijo, pueden haber estado en el mismo rango de precios. Por lo tanto, la edición emprendida por Francisco Monteiro también puede haber estado guiada por intereses comerciales, especialmente dada la división de la obra en tres pequeños volúmenes. Cuando se consultan las dos versiones del Panegírico de D. João III (I74O y I79I), es evidente que Monteiro se basó exclusivamente en el texto de la edición de I740 y no utilizó ninguna otra fuente, por ejemplo, el manuscrito indicado o los papeles que José Barbosa afirma haber encontrado. El texto de la edición de i79I es idéntico al de la edición de I740, también sin las líneas suprimidas en esa edición en relación con la versión manuscrita que se encuentra en la BNP.

\section{EL PANEGIRICO DA INFANTA D. MARIA}

\section{EL MANUSCRITO}

Mientras que el Panegírico de D. João III se publicó en I740, junto a la reedición de las Notícias de Portugal, otro panegírico atribuido a João de Barros ya acompañaba a la primera edición de las Notícias: el Panegírico da infanta D. Maria.

Las Notícias de Portugal se publicaron en Lisboa en el Taller de Craesbeeck en I655. La obra aporta ocho discursos y también algunos elogios: los dos primeros escritos por el propio Severim -el «Elogio de Frei Bernardo de Brito» (fl. 278) y el «Elogio de Évora» (fl. 289)-, además del «Elogio d'el rei Dom João de Portugal III

52. Panegyricos do grande João de Barros. Fielmente reimpressos conforme sua antiga Linguagem =ano de 1533. Por Joaquim Francisco Monteiro de Campos Coelho, e Soiza, Lisboa, Oficina de António Gomes, 1791. Hemos consultado ejemplares de esta edición depositados en el Real Gabinete Português de Leitura, en Rio de Janeiro.

53. SILVA, 1962: 107 . 
do nome» (fl. 29I), de António de Castilho, y el «Panegírico a mui alta e esclarecida princesa infanta Dona Maria nossa Senhora» (fl. 306), atribuido a João de Barros. En referencia al «Elogio» de António de Castilho, Severim de Faria escribió:

O Elogio do Rei D. João III é feito por António de Castilho, cronista mor que foi deste reino, e do conselho do rei D. Sebastião, e seu embaixador na Inglaterra, e um dos homens que melhor falaram a língua portuguesa, a juízo de todos os doutos: e assim por esta causa, como por ser de um rei, que governou com maior acerto, e felicidade a Portugal, me pareceu muito conveniente tirá-lo das trevas do esquecimento em que estava sepultado; pois é digníssimo sair à luz, e andar nas mãos de todos ${ }^{54}$.

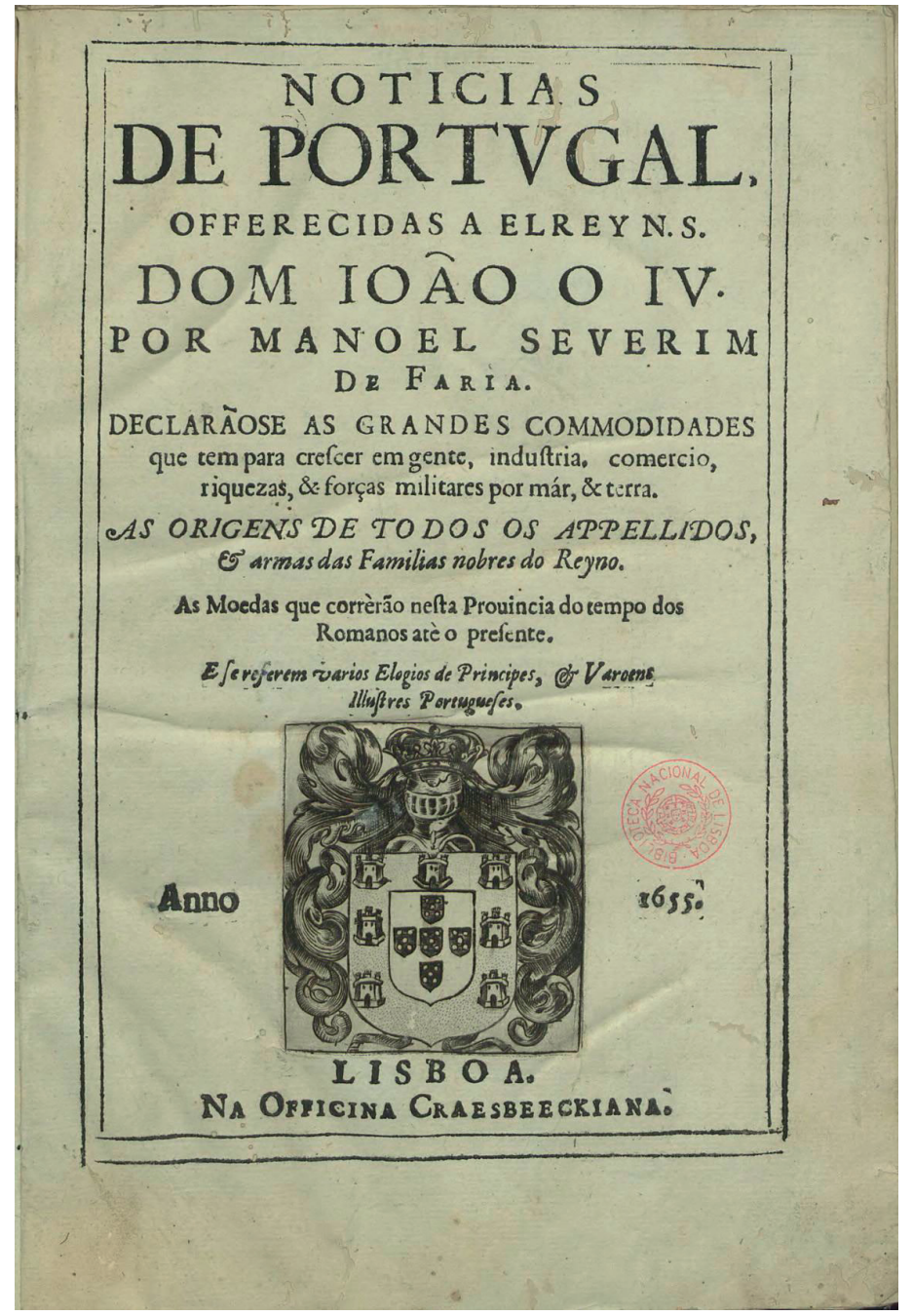

FIGURA 3 FOTO DE LA PORTADA DE LAS NOTÍCIAS DE PORTUGAL CON EL ESCUDO REAL. LISBOA, BNP. CONSULTADO EL 20 DE JUNIO DE 2019. URL: HTTP://PURL.PT/28506

54. FARIA, 1655: s/p. 
También dedicó las siguientes palabras al Panegírico da infanta D. Maria:

«No mesmo estado passava esquecido o Panegírico da Senhora Infanta D. Maria [...]. Foi composição do nosso grande João de Barros, o qual como seu pai era moderador de Viseu, celebrou com este Panegírico a boa sorte daquela cidade, quando o rei D. João a deu à senhora infanta com título de duquesa dela»55.

Obsérvese en los pasajes anteriores cómo Manuel Severim de Faria se refiere a la condición manuscrita de los textos en proceso de publicación. Publicarlos significaría sacarlos de la «oscuridad del olvido» y hacerlos circular en las manos de todos. Estas palabras sugieren cómo Severim percibía el manuscrito y el impreso, y cómo jerarquizaba estas formas de comunicación.

En esa civilización escrita, marcada por el método de reproducción tipográfica, ambas modalidades -impresa y manuscrita- constituían dos posibilidades de escritura, dos usos distintos que cumplían funciones diferentes. Por lo tanto, si «caminar impreso» significaba «caminar en las manos de todos»-para usar las palabras de Severim-, el manuscrito podía convertirse en un instrumento de privacidad y secreto, algo que sólo se lograba si el texto no se entregaba para su impresión ${ }^{56}$. Además de estar asociado a una circulación más limitada y a una mayor privacidad, el manuscrito podría mantener su estructura abierta. Al no estar fijado definitivamente, fue objeto de reescritura y reelaboración continua ${ }^{57}$.

Aunque la tipografía permitió fijar el texto en mejores condiciones y lo abarató, haciendo que el libro impreso alcanzara una gran difusión, muchos textos permanecieron manuscritos durante mucho tiempo, o nunca llegaron a ser publicados. Ana Paula Megiani cita tres textos producidos en el ambiente de Severim de Faria y relacionados con sus acciones: los Diálogos das grandezas do Brasil, escritos en I6I8 por Ambrósio Fernandes Brandão y publicados sólo en el siglo XIX; la História do Brasil de Fr. Vicente de Salvador, terminada en I627 y también publicada sólo en el Ochocientos; e Histórias dos animais e árvores do Maranhão, escritas posiblemente entre I624 y I627 por el Fr. Cristóvão de Lisboa, hermano de Manuel Severim de Faria, y publicadas más tarde ${ }^{58}$.

Algunos estudiosos cuestionan las razones por las que tales obras permanecieron manuscritas, retrasando la aparición de una primera historia impresa de Brasil. Una de las razones puede haber sido el flujo de envío de textos a Évora, con Severim posiblemente sin darse cuenta de cómo leerlos y organizarlos. En su casa se concentraba el mayor volumen de información narrativa y descriptiva sobre los estados de Brasil y el Gran Pará y Maranhão, procedente de todas las partes del imperio. Pero el hecho de que no se imprimieran no significa que no se conocieran y se reprodujeran en forma manuscrita. Muchos textos del propio Severim de Faria no fueron impresos, lo que puede demostrar su apego al manuscrito ${ }^{59}$.

55. Ibídem.

56. Álvarez, 1997: 10-12, 45

57. ChARTIER, 2014

58. MEGIANI, 2014: 70 .

59. Ibid: $74-75$. 
Sin embargo, las palabras de Severim nos llevan a creer que mostró aprecio por el texto impreso sobre el manuscrito. A pesar de que muchos de sus textos no fueron publicados y muchos manuscritos circulaban en su entorno literario, Severim de Faria se comprometió a publicar textos inéditos de António de Castilho y João de Barros, lo que reforzaba el peso que estos autores tenía para él. Tanto el Elogio do rei D. João III como el Panegírico da infanta D. Maria quedaron «olvidados» en los círculos literarios, por lo que Severim de Faria emprendió la tarea de publicarlos. Sin embargo, es difícil saber si Faria ya conocía la versión manuscrita del Panegírico da infanta D. Maria cuando publicó la Vida de João de Barros en I624, o si conoció la versión manuscrita después de esa fecha, ya que en las pocas palabras que dedica al panegírico no comenta cómo o cuándo adquirió el texto.

Por otra parte, la cuestión parece aclararse un poco más cuando leemos la sección titulada «Aos leitores» de las Notícias de Portugal, en la que Faria informa que, cuando publicó los Discursos vários políticos en $\mathrm{I} 624^{60}$, ya tenía la obra Notícias de Portugal prácticamente terminada y lista para ser publicada:

No ano de 1625, dei a estampa alguns Discursos e Elogios para instrução política das Artes, em que hão de ser doutrinados os mancebos nobres da República, conforme os preceitos do filósofo: e tendo eu naquele tempo uma obra grande, que intitulava Notícias de Portugal e suas conquistas, já quase em estado para se poder imprimir, como testificam os doutores Fr. António Brandão, Geral que foi de Alcobaça, e António de Sousa de Macedo, que então a viram; contudo como as coisas daqueles anos para cá tiveram tão grande mudança, recresceram tais inconvenientes, que me sobrestive na execução deste intento. Porém entendendo eu, que não seria de menor serviço do bem público alguns Discursos dos muitos, que nesta obra se continha sobre diversas matérias, assim políticas, como de vária lição, me pareceu comunica-lo a todos, e pelo que participaram de seu primeiro original, dar-lhe o título de Notícias de Portugal ${ }^{61}$.

Los Discursos vários políticos deben haber sido una preparación del autor para lo que sería su mayor obra, las Notícias de Portugal, como parece indicar el pasaje: «Costumam os arquitetos quando intentam levantar alguma fábrica, desenhar primeiro em uma pequena traça, para depois se acertar melhor o edifício» ${ }^{62}$. Severim de Faria usó los Discursos para trabajar en su estilo y así prepararse para obras más grandes, como él mismo indica en la dedicatoria.

El pasaje anterior hace pensar también en lo siguiente: si en I624, cuando Severim de Faria publicó los Discursos vários políticos, ya tenía prácticamente terminadas las Notícias de Portugal, es posible que los textos destinados a la sección «Elogios» (entre ellos el Panegírico da infanta D. Maria) estuvieran ya en sus manos. Pero lo más probable es que no lo fueran, porque, además, estos textos forman una especie de apéndice al resto de la obra. Añade a esto el hecho de que el propio Severim declaró en el prólogo de las Notícias que el Panegírico da infanta D. Maria y el Elogio do rei

6o. No sabemos si, por un descuido, Faria afirma que 1625 fue el año de la publicación de los Discursos vários políticos, y no 1624, como está impreso en la portada de los Discursos.

61. FARIA, 1655, «Aos leitores»: s/p.

62. Ibid. 
D. João III permanecían «olvidados», de ahí su propósito de publicarlos. Si en I624 ya estaba en posesión de ese panegírico de Barros, no habría razón para no citarlo en su biografía dedicada al letrado portugués. Por lo tanto, lo más probable es que se enterara de este texto más tarde.

Hay otro punto que refuerza la idea de que Manuel Severim de Faria no tenía conocimiento previo del Panegírico da infanta D. Maria. En la Vida de João de Barros, el biógrafo no sólo habla de las obras publicadas, sino que también menciona las que João de Barros dejó iniciadas o trató de escribir ${ }^{63}$. Cita textos como Europa, Africa e Santa Cruz; Tratado de causas ou problemas morais; Abusões do tempo; Geografia universal; e Sphera da instructura das cousas a partir de las mismas referencias dejadas por Barros en sus textos publicados, y confirma la existencia de tales composiciones a partir del testimonio de personas que supuestamente tuvieron contacto con los manuscritos. A pesar de citar estos textos de João de Barros que no fueron publicados, no se hizo ninguna referencia a los manuscritos panegíricos atribuidos al mismo autor, entre ellos el Panegírico da infanta D. Maria.

\section{LA PUBLICACIÓN}

La única información sobre el Panegírico da infanta D. Maria dejado por Manuel Severim de Faria se encuentra en la sección «Aos leitores» de las Notícias de Portugal, como se transcribió anteriormente ${ }^{64}$. Aunque no mencionó este panegírico en la biografía dedicada a João de Barros, Severim de Faria si propuso en ese ensayo biográfico el lugar de nacimiento para el erudito portugués, Viseu, y confirmó este dato nuevamente en las Notícias, cuando afirmó que Barros celebraba la indicación de la infanta D. Maria como duquesa de esa ciudad, cuyo padre era residente.

António Baião consideraba la ciudad de Viseu «como posible y hasta probable» lugar de nacimiento de João de Barros. Después de él, Alexandre de Lucena e Vale hizo de la posibilidad una certeza, extrayendo del propio texto la confesión del lugar de origen del autor que, de acuerdo con Lucena, era posible reconocerse en el siguiente pasaje:

Que dias há, que este vosso povo, derramado pelos desertos desabitados da razão, espera por V. Alteza! Grandes caminhos se me abriam aqui de seu louvor, mas dirão que não guardo o decoro que devo à pátria em publicar seus defeitos, por ser mãe, que me gerou65.

63. «Porém quanto mais são estimadas as obras com que saiu à luz, tanto maior pena nos podem causar as que deixou começadas, e intentadas, que sem dúvida seriam de grande ornamento para este reino»-escreve ele, afirmando ainda que, apesar de não se poder «lograr a excelência destes volumes, apontarei aqui, ao menos, a traça, a disposição deles, para ainda assim serem de proveito (como já foram) aos curiosos». FARIA, 1624: XLI.

64. «No mesmo estado passava esquecido o Panegírico da Senhora Infanta D. Maria [...]. Foi composição do nosso grande João de Barros, o qual como seu pai era morador de Viseu, celebrou com este Panegírico a boa sorte daquela cidade, quando o rei D. João a deu à senhora infanta com título de duquesa dela». FARIA, 1740: s/p.

65. BARROS apud FARIA, 1655: 322; VALE, 1970. 
El panegírico se habría escrito para celebrar el contrato firmado entre el rey D. João Ill y su hermana, cumpliendo una cláusula del matrimonio del rey D. Manuel con la reina Leonor, infanta de Castilla y madre de D. María. El contrato del último matrimonio de D. Manuel preveía que la hija mayor, en caso de no haber hijo varón, recibiría a partir de los I6 años una cantidad de 400.00o pliegues de oro castellano. La donación de la ciudad de Viseu a la hermana, así como la de la ciudad de Torres Vedras, habría sido hecha por D. João III para satisfacer parte de esta importancia. Alexandre de Lucena e Vale localizó en el ANTT el borrador del contrato, con fecha de I544. António de Oliveira, por su parte, afirma que no fue éste el año en que se formalizó el contrato, sino 1545, según consta en el libro de la Chancelaria de D. João $\mathrm{III}^{66}$. En cualquier caso, considerando las dos posibilidades, el Panegírico da infanta D. Maria habría sido escrito en I544 o I545 y, en el texto, el autor -identificado por Severim como João de Barros- habría hecho referencia a su ciudad natal, corroborando su origen visiense, tal como la defendía Alexandre de Lucena e Vale.

Del panegírico sobre lienzo hay una copia manuscrita en el ANTT. Hasta donde podemos ver, este es el único manuscrito del panegírico conocido. El texto está en la Colecção S. Vicente, libro I5, título I, páginas 86-94. Gracias al trabajo de digitalización del archivo, la colección está disponible en el sitio web de la institución ${ }^{67}$.

En comparación con la edición impresa, el manuscrito tiene lagunas. Primero, con relación a la disposición del texto. Al transcribirlo, el copista comenzó a escribir en la misma hoja de otro texto -el Livro da verdadeira nobreza, del fraile Francisco Barreiros, sobrino de João de Barros- de modo que la parte final del texto de Barreiros no fue escrita y fue reemplazada por el panegírico. El Livro da verdadeira nobreza está numerado del i al 86 y el panegírico ocupa las páginas 86 a 94. Entre las hojas 89 y 90 hay una advertencia, posiblemente hecha por los responsables de la digitalización, con las siguientes palabras: «Falta o fim da obra de Frei Francisco Barreiros que continuava na folha 88 , da numeração riscada, e que se devia estender até a 94. Pela numeração em vigor vê-se que já faltava quando o livro foi encadernado no séc. XVIII».

Del análisis del documento se desprende que los dos textos (el tratado y el panegírico) son de la misma letra, de la misma mano, del mismo escritor, y se imputan a los siglos XVI o XVII, ya que la letra, denominada por algunos paleógrafos como cursiva, gótica tardía o humanista, y por la Escola de Coimbra como «semicursiva», es una letra de transición. La diferencia más obvia entre los dos textos es el cuidado que se pone en la escritura: mientras que en el tratado es más relajada, la escritura del panegírico es más pausada, hecha con más cuidado y lentitud. La dificultad para diferenciarlas es precisamente el hecho de que están muy estandarizadas y presentan las características más comunes de este estilo caligráfico: las abreviaturas más recurrentes: q', cõ, hũ, el módulo, el ductus, el peso, la inclinación e incluso las

66. Oliveira, (1992): 215-220.

67. La Colección de San Vicente abarca una cronología de 1499 a 1712 y está compuesta por numerosos volúmenes, entre ellos el «Libro 15», compuesto por textos de diversos perfiles. Lisboa, ANTT. Consultado el 18 de mayo de 2019. URL: https://digitarq.arquivos.pt/details?id=4166309. 


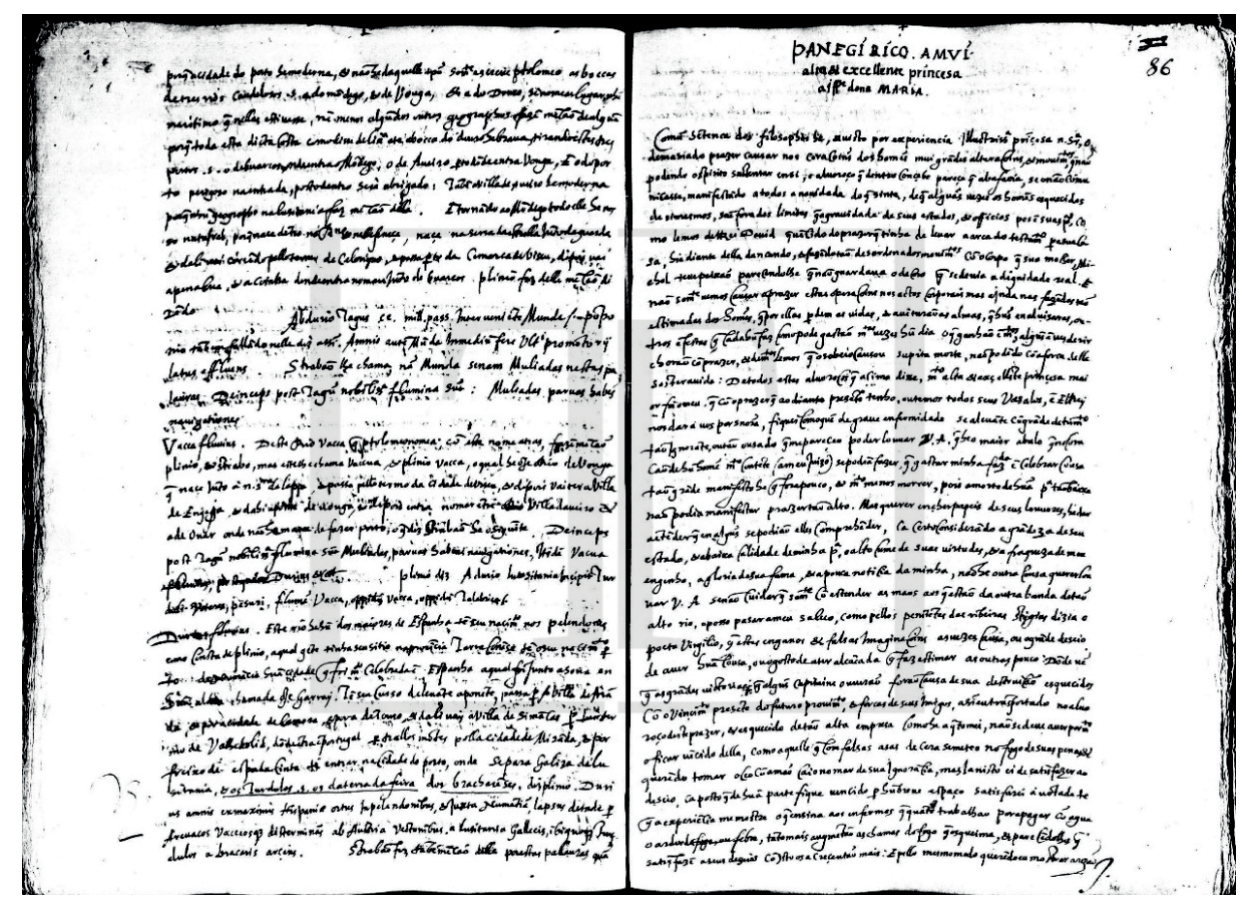

FIGURA 4. HOJA INICIAL DEL PANEGIRICO. A MUI ALTA \& EXCELLENTE PRINCESA A IFF. DONA MARIA (SEGUNDA COLUMNA). EN LA PRIMERA COLUMNA APARECE LA ÚLTIMA PARTE DEL LIVRO DA VERDADEIRA NOBREZA, DEL FRAILE FRANCISCO BARREIROS, CUYO FINAL NO INTEGRA LA ENCUADERNACIÓN ORIGINAL. FOTO DEL FOLIO 100 DEL ARCHIVO DIGITAL. LISBOA, ANTT. CONSULTADO EL 20 DE JUNIO DE 2019. URL: HTTPS://DIGITARQ. ARQUIVOS.PT/VIEWER?ID $=4166309$

conexiones. Para ambos, todo estaría dentro del «patrón» común. En relación con la estilística y la «ortografía»-palabra utilizada aquí con las advertencias necesarias para el período- no hay diferencias marcadas que caractericen diferentes puños ${ }^{68}$.

En relación con la compaginación hecha entre el manuscrito y el impreso, identificamos decenas de pasajes presentes en el primero y faltantes en el segundo. De estos pasajes, cinco son citas en latín, que sólo existen en la publicación. Por otro lado, identificamos solo nueve pasajes en el manuscrito que no aparecen en el texto editado. También hemos observado pasajes que tratan del mismo tema -en ambas versiones- pero escritos de manera diferente. Todavía hay algunas pequeñas variaciones entre una frase y otra -al comparar el manuscrito con la versión impresa- como el intercambio de palabras de lugar, para responder a una cuestión de estilo por parte del editor del texto, suponemos nosotros.

Sin embargo, queda una pregunta: ¿el texto impreso estaba basado en este manuscrito en particular? Si la respuesta es afirmativa, el editor Manuel Severim de Faria «perfeccionó» el texto y añadió numerosos pasajes al original, de acuerdo con la práctica de la escritura de la época, sobre todo si se tiene en cuenta la condición «abierta» del manuscrito. De los pasajes exclusivos que pudimos identificar en el texto impreso, algunos son pequeños, otros presentan una extensión considerable, por lo que el texto editado es mucho más grande que el manuscrito. Aunque el

68. Para el análisis paleográfico de este documento, contamos con la ayuda de Alícia Duhá Lose. 
manuscrito no está dividido en párrafos, tiene una notación única a lo largo de sus páginas -dos puntos «:» En el texto impreso, muchas de las marcas de los párrafos coinciden con esta notación.

Por otra parte, Manuel Severim de Faria puede haber utilizado otro texto manuscrito para la edición que realizó. Después de su muerte, su librería emigró a Lisboa y pasó a formar parte de la biblioteca del Conde de Vimieiro. En el siglo XVIII, D. Francisco Xavier de Meneses presentó a la Academia Real da História Portuguesa la lista de documentos e impresos que pertenecían a Severim, procedentes de la indagación realizada en la librería del conde. Esta búsqueda -la más completa para aquellos que desean conocer los títulos originalmente reunidos por lo eborense- fue parte de los esfuerzos de los miembros de la Academia para conocer la producción impresa y manuscrita existente en el reino ${ }^{69}$. Al quejarse de la falta de conocimiento de las librerías de manuscritos portugueses, D. Francisco Xavier de Meneses convoca a los eruditos a la tarea de recopilar los títulos producidos. Y él mismo comienza la exploración de la librería del Conde de Vimieiro:

A Livraria do Conde do Vimieiro será a primeira, de que se dê conta; compõem-se de quatrocentos manuscritos, e livros raros, a maior parte do Erudito, e llustre Chantre de Évora, Manoel Severim de Faria, alguns de parentes seus muito cientes, outros do preclaro varão Martim Afonso de Sousa, que este título lhe dá seu sutilíssimo mestre o grande Pedro Nunes no princípio das suas obras matemáticas, e o juízo que faço da boa fé, e da erudição dos que formaram, e conservaram as Livrarias, me serve muito para o crédito, que dou aos manuscritos. O Conde de Vimieiro está retirado nesta vila, Diogo Coelho seu criado que vive em umas casas junto às suas em S. Francisco, conserva estes livros cuidadosamente, e a mostra com aviso meu $^{70}$.

De la consulta de los títulos reportados, nos encontramos con varios documentos raros, entre los que destacan originales y copias de despachos, cartas, instrucciones y regimientos para Brasil en la época del gobernador Tomé de Sousa; crónicas escritas por Rui de Pina a D. João II; documentos originales pertenecientes al reinado de D. João IV sobre rentas reales; una crónica escrita por Duarte Galvão a D. Afonso Henriques y un diálogo compuesto por Diogo do Couto entre un soldado y un noble de la India.

Ya en las noticias presentadas a la Academia el I de junio de I724, se puede leer la siguiente descripción: «Panegírico à infanta D. Maria filha do rei D. Manuel. É o panegírico de João de Barros que corre impresso, mas tem umas advertências de D. Jeronimo Mascarenhas, e muitas na dedicatória, que pertencem ao governo da Duquesa de Mântua em I638 $»^{71}$. En la misma relación presentada por el Conde de Ericeira a la Academia Real da História Portuguesa hay todavía algunas advertencias críticas sobre las Décadas de João de Barros, principalmente relacionadas con errores de impresión, útiles para que se hicieran nuevas impresiones de esos

\footnotetext{
69. SYLVA, 1724, num. XIII: 2-3.

70. Ibid: 4 .

71. SYLVA, 1724, num. XV: 4 .
} 
libros, así como dos referencias más puntuales al humanista en discusión. Por otra parte, no se menciona el Panegírico de D. João III, por lo que Severim de Faria nunca publicó ese texto, pues ni siquiera era consciente del mismo ${ }^{72}$.

De acuerdo con el Conde da Ericeira, un ejemplar manuscrito del panegírico dedicado a la infanta D. Maria integró la librería de Manuel Severim de Faria y fue adquirido posiblemente después del año I624, tras la publicación de la biografía del erudito del siglo XVI (la cita del párrafo anterior se refiere al año I638). La descripción que hace el Conde de Ericeira de este manuscrito es reveladora, especialmente en relación con las advertencias del documento y la referencia a una dedicatoria: el manuscrito del panegírico que perteneció a Manuel Severim de Faria no podría haber sido el transcrito con el Livro da verdadeira nobreza, del fraile Francisco Barreiros, ya que ese documento ni siquiera contiene tales advertencias, y mucho menos una dedicatoria.

Además, teniendo en cuenta que el texto manuscrito del panegírico disponible en el ANTT está en la secuencia de otro y no es un texto independiente, este manuscrito específico tampoco puede haber sido el que integró la librería de Manuel Severim de Faria; de lo contrario, el Conde de Ericeira habría informado el Livro da verdadeira nobreza y no el panegírico, que aparece al final de esa obra (en su búsqueda el Conde de Ericeira no cita ningún Livro da verdadeira nobreza). Por otra parte, es posible que el texto del panegírico perteneciente a Severim haya sido copiado de ese manuscrito en particular -dadas las similitudes entre el texto manuscrito y el impreso-y Severim añadió sus propios pasajes al original para su impresión. En cualquier caso, a falta de otro manuscrito que arroje luz sobre estos asuntos, nos queda este documento específico, que parece ser el único superviviente. Sobre él, debemos plantear algunas preguntas, por ejemplo, sobre su autoría.

Nada en el documento manuscrito identifica a João de Barros como el autor del texto. Ni al principio ni al final aparece el nombre o cualquier otra referencia al erudito portugués. Debido a las condiciones en que se encuentra el texto, transcrito en secuencia de otro, algunos atribuyeron la autoría del panegírico al fraile Francisco Barreiros, autor del Livro da verdadeira nobreza. Este fue el caso de Maria do Rosário Cruz, en su estudio sobre As regências na menoridade de D. Sebastião $0^{73}$.

En el contexto de la sucesión al trono portugués, tras la muerte del monarca D. Sebastião, la infanta D. Maria fue indicada como posible candidata. La hija del tercer matrimonio de D. Manuel era una de las reservas políticas de la corte portuguesa de Avis y, una vez comprometida la ascendencia real, se avivó el debate sobre su nombre, que finalmente fracasó. Sin embargo, la memoria de sus derechos y la defensa de su persona no fueron olvidadas. D. Maria representaba para muchos una esperanza como posible continuación del cardenal D. Henrique. Era además una personalidad en el campo cultural y un modelo de nobleza, cualidades observadas por Maria do Rosario Cruz en el «Panegírico a mui alta, e excellente princesa a iff. dona Maria». Al llamar la atención sobre el hecho de que el autor del panegírico expuso el debate

72. SYLVA, 1724, num. XXVI: 7; num. XXX: 2, 4.

73. CRUZ, 1993 
renacentista sobre el valor y el significado de la nobleza y lo que se esperaba del noble de sangre, la historiadora atribuyó el panegírico al fraile Francisco Barreiros, que ya había debatido este tema no sólo en el Livro da verdadeira nobreza, sino también en las dedicatorias dirigidas a D. María. El panegírico, en resumen, se presentó como una apología de la posición política de la infanta ${ }^{74}$.

La conclusión de Maria do Rosario Cruz es bastante plausible, sobre todo por las condiciones en que se encuentra el texto: transcrito siguiendo el Livro da verdadeira nobreza y con discusiones acordes con las de Francisco Barreiros. Como en el texto no hay pruebas que revelen su autoría, podemos estar ante un escrito de Barreiros, lo que nos lleva a cuestionarnos: ¿Manuel Severim de Faria habría atribuido incorrectamente la autoría del Panegírico da infanta D. Maria a João de Barros?

Severim de Faria también escribió sobre la nobleza y dedicó un discurso de sus Notícias de Portugal al tema. En su Discurso III, el autor trata de la nobleza de las familias de Portugal con datos acerca de su antigüedad y sobre el origen de los apellidos y escudos de los linajes nobles, y cita a Francisco Barreiros como uno de los encargados de escribir sobre el tema en Portugal. Según Severim, Barreiros se habría dedicado al tema escribiendo el Livro da verdadeira nobreza, que no concluyó. La obra fue compuesta por orden del cardenal D. Henrique, y un sobrino del autor, Manoel de Azevedo de Barros, la mantuvo en su poder 75 .

El propio Manuel Severim de Faria cita la obra del fraile Francisco Barreiros con la información de quien la guardaba, lo que indica la posibilidad de que el eborense haya tenido contacto con esa obra y con el panegírico que la acompañaba -en el caso del mismo manuscrito bajo la custodia del ANTT. Según Severim, el trabajo no se completó, como se desprende del documento del ANTT. Si Severim de Faria se basó realmente en este manuscrito para la edición emprendida, la autoría se atribuyó a João de Barros sin que el documento aportara ningún dato objetivo sobre esta imputación.

Después de que Manuel Severim de Faria fijara la autoría del panegírico, ningún otro autor que se ocupara del texto cuestionó posteriormente esa información. En su História genealógica da casa real portuguesa, al escribir sobre D. María y lo que se había producido de ella, D. António Caetano de Sousa citó el panegírico atribuido a João de Barros como un excelente elogio dedicado a la infanta:

[...] louvam com elogios não só os nossos escritores, mas muitos dos estrangeiros, como mais largamente escreveu Fr. Miguel Pacheco na sua Vida, que se imprimiu em Lisboa no ano de 1675 na língua castelhana com excelente estilo, de que formamos este breve Elogio. O insigne escritor João de Barros, escreveu em seu louvor um excelente Panegírico, que o chantre Manoel Severim de Faria imprimiu no fim do seu livro das Notícias de Portugal, no ano de $1655^{76}$.

74. Ibídem: 273-275. Cabe destacar que el fraile Francisco Barreiros escribió un «Egloga pastoril em louvor da infanta D. Maria», como atestigua Diogo Barbosa Machado (1741, vol. II: 336). Oliveira (1992): 217, nota 1, sostiene que el autor del panegírico debe ser un laico y no un fraile franciscano y mantiene para este texto la autoría que seguía entonces - João de Barros

75. MACHADO, 1741, vol. II: 336; FARIA, 1655: 120.

76. SOUSA,1737, tomo I: 477 . 


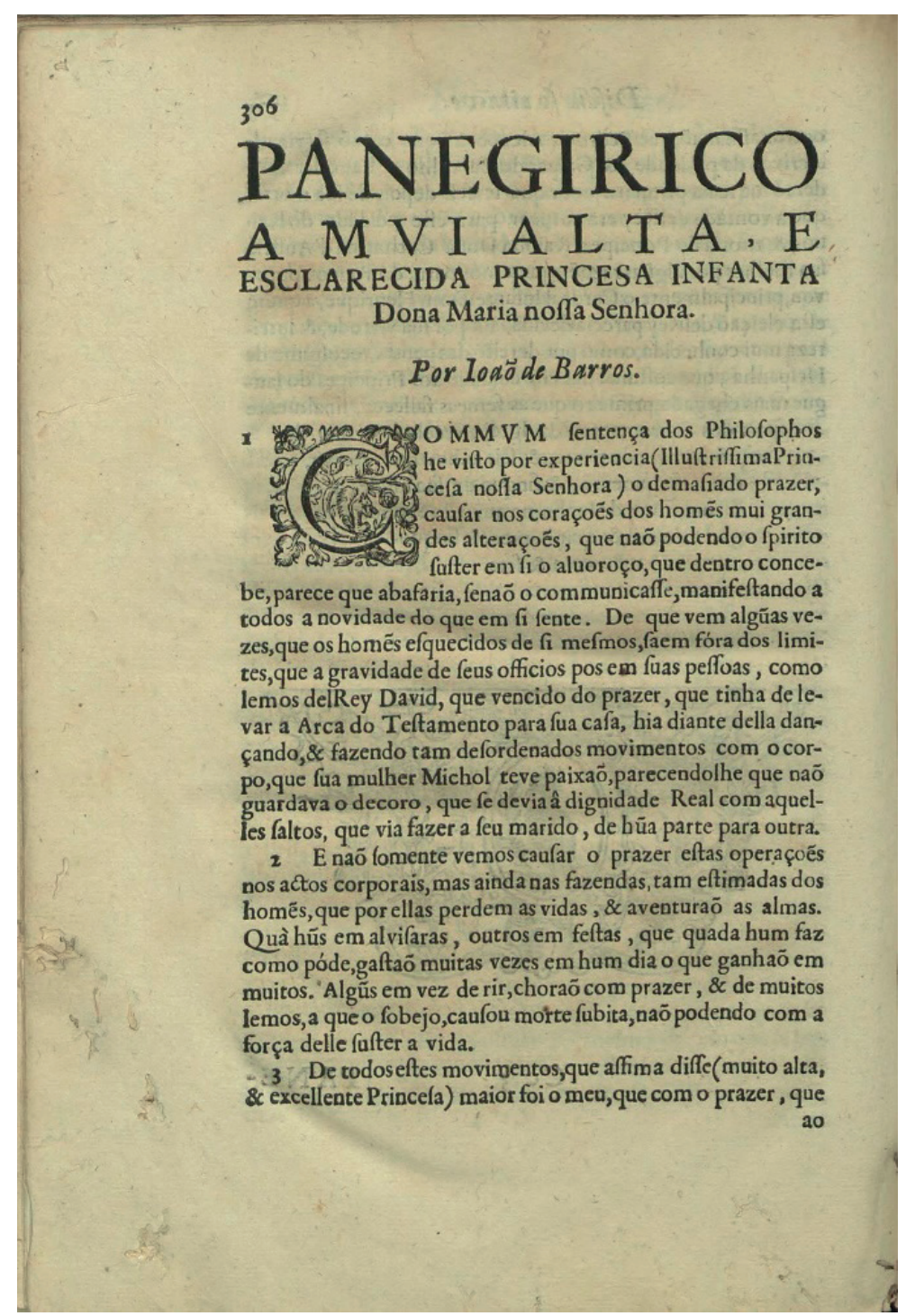

FIGURA 5. HOJA INICIAL DEL PANEGÍRICO A MUI ALTA E ESCLARECIDA PRINCESA INFANTA DONA MARIA NOSSA SENHORA, ATRIBUÍDO A JOÃO DE BARROS POR MANUEL SEVERIM DE FARIA E IMPRESO EN SUS NOTÍCIAS DE PORTUGAL (1655). EL TÍTULO DEL PANEGÍRICO NO SE CORRESPONDE CON EL QUE SE ENCUENTRA EN EL MANUSCRITO BAJO LA CUSTODIA DEL ANTT: PANEGIRICO. A MUI ALTA \& EXCELLENTE PRINCESA A IFF. DONA MARIA. LISBOA, BNP. FOTO DEL FOLIO 306. CONSULTADO EL 20 DE JUNIO DE 2019. URL: HTTP://PURL.PT/28506

En la Bibliotheca lusitana, Diogo Barbosa Machado también citó este panegírico en su entrada a João de Barros y enumeró las ediciones del texto hasta el momento en que escribió: la de I655 de Manuel Severim de Faria, la de I675 de Fr. Miguel Pacheco y la de 1740 de José Barbosa ${ }^{77}$. Miguel Pacheco, autor de una biografía de la infanta D. Maria, reprodujo íntegramente el texto del panegírico editado por Manuel Severim de Faria y dedicó a la obra las siguientes palabras:

77. MACHADO, 1741, vol. II: 608 . 
Guardamos para o prosterno lugar destes Elogios, o que merecia o primeiro, por ser do insigne historiador João de Barros, que citamos há pouco, e pela elegância e grave estilo, com que escreveu; mas como este panegírico, que fez à senhora infanta em português, é tão difuso, reservamo-lo para aqui, como separado dos demais, sem versão em outra língua, por respeito que se deve ao autor; [...]. O curioso que quiser lê-lo, o achará do mesmo modo que em seu original. [...]. Escreveu Barros esta obra com tanta erudição e lugares da escritura divina e humana, que havendo muitas, em suas Décadas, tão célebres na Europa, a presente em seu gênero vence todas, e a igualam alguns ao Panegírico que escreveu Plínio a Trajano ${ }^{78}$.

Como se puede ver en estos pasajes, se mantuvo la autoría del panegírico fijado por Severim de Faria, responsable de la primera impresión del texto. Todos los autores que se dedicaron más tarde a ese escrito hicieron referencia a la edición de I655.

En el siglo pasado, dos historiadores trataron de dar respuestas a las incertidumbres planteadas por Manuel Severim de Faria en relación con el lugar de nacimiento de João de Barros. En la Vida de João de Barros, Severim había escrito:

Nasceu João de Barros pelo ano de 1496. Sobre o lugar da pátria há várias opiniões; porque como o nascimento dos bons, segundo Santo Ambrósio, seja bem comum, pretendem muitos ser dele participantes. Uns afirmam que é de Braga, confundindo (pode ser) seu nome com o doutor João de Barros, autor da descrição de Entre Douro e Minho que dele foi natural; outros o fazem de Viseu onde seu pai foi morador e ainda tem parentes; alguns de Vila Real. E finalmente muitos o têm por natural de Pombal, porque aí teve sua fazenda e ali se retirou muitas vezes a uma quinta sua e esta escolheu para vivenda da última velhice que é o tempo que os homens tornam com natural desejo a buscar a pátria para acabar, parece, o círculo da vida onde começaram ${ }^{79}$.

El primero de ellos, António Baião, que documentó la vida y la obra de João de Barros, dijo que no encontró pruebas objetivas sobre el lugar de su nacimiento. Luego de refutar la hipótesis de Braga, Vila Real y Pombal, el historiador concluyó: «Fica apenas de pé como possível e até provável o nascimento em Viseu» ${ }^{80}$. Alexandre de Lucena e Vale fue más allá en este tema, al centrarse en el texto del Panegírico da infanta D. Maria. Para el historiador de Viseu, João de Barros habría afirmado indiscutiblemente en su panegírico que era nativo de esa ciudad. Al proponer una nueva interpretación del texto - «a sua única e exata interpretação»- Lucena extrajo del panegírico varios pasajes que, según él, demostrarían dos cosas: I) el panegírico había sido escrito para celebrar el evento en que D. João III hizo a su hermana la duquesa de Viseu; 2) el autor, João de Barros, había indicado en el texto que era natural de Viseu cuando se colocó como vasallo del nuevo propietario de la ciudad. Frases como «De todos estes movimentos, mui alta e excelente princesa, maior foi o meu, que com o prazer que ao presente tenho ou temos todos os seus vassalos, em el rei nos dar a vós por Senhora [...]» o «[...] o prazer que temos os seus vassalos de

\footnotetext{
78. PACHeCO, 1675: 143-144. El panegírico ocupa las páginas 144 a 164 de la obra del fraile Miguel Pacheco.

79. FARIA, 1624 .

80. BAIÃO, 1998: VII-VIII.
} 
ser o dia de hoje mui contentes [...]» indicarían la fidelidad de los acontecimientos, es decir, el nombramiento de la infanta D. María como Duquesa de Viseu. El autor del panegírico no se referiría, pues, a la condición de la princesa como tal, como miembro de la familia real, sino como propietaria de Viseu. Otras expresiones que se encuentran en el panegírico, como «Senhora nossa», «nós vossos vassalos», «este vosso povo» se habrían utilizado no en el sentido genérico, amplio, en referencia a la princesa, sino en referencia a la nueva Duquesa de Viseu. Para Alexandre de Lucena e Vale, estas frases por sí solas ya indicarían la procedencia de João de Barros, pues escribe, como hijo de Viseu, como vasallo de la nueva dama y duquesa.

Pero además de estos pasajes, Lucena y Vale destaca otro que, a su entender, es decisivo para revelar el origen visiense de João de Barros:

Aqui poderia eu dizer, prudentíssima princesa, que nela se pode mostrar este grande homem sabedor, que meteu aos outros no caminho da verdade. Que dias há, que este vosso povo, derramado pelos desertos desabitados da razão, espera por V. Alteza! Grandes caminhos se me abriam aqui de seu louvor, mas dirão que não guardo o decoro que devo à pátria em publicar seus defeitos, por ser mãe, que me gerou. Oh! Grandíssima prudência d'el-rei nosso senhor entregar neste tempo um povo a quem o havia de restituir a estado de maior quietação e repouso! Grandíssima clemência de $V$. Alteza, aceitar a governança dele pelo salvar! [...]. Muito devemos ao rei, que nos deu a tão alta princesa, muito devemos a $\mathrm{V}$. Alteza, que nos aceitou por seus ${ }^{82}$.

Para el historiador, tales pasajes resultarían ininteligibles fuera de su interpretación propuesta, y concluye: «O Panegírico, na sua concepção (o elogio da nova donatária do Senhorio e Ducado de Viseu) na sua urdidura e finalidade (o sentido de remissão do pecado de Viseu e sua conciliação com el rei), na sua generalidade do contexto e no pormenor de todas as frases e passos referidos -é a confirmação, a prova de ser Viseu a naturalidade de João de Barros» ${ }^{82}$.

El argumento desarrollado por Alexandre de Lucena e Vale tiene sentido dentro de su interpretación propuesta, es decir, que el panegírico fue escrito para celebrar la ocasión en que la infanta D. María fue nombrada duquesa de Viseu. Los pasajes que ha extraído son elocuentes a este respecto. Sin embargo, al tomar a João de Barros como autor del panegírico, sin cuestionar la imputación conferida por Manuel Severim de Faria, sus conclusiones resultan frágiles. En primer lugar, los extractos del panegírico podrían aplicarse también a Francisco Barreiros, cuyo origen visiense no está en duda $^{83}$. En segundo lugar, el pasaje más revelador de la indicación de João de Barros, el supuesto autor, se refiere a la «pátria» (¿Viseu?) como «a mãe que me gerou», como se lee en el extracto anterior, solo se encuentra en la edición impresa. En el texto manuscrito no existe ese pasaje específico. La pregunta entonces sigue siendo: ¿habría escrito Manuel Severim de Faria esa frase y atribuido una procedencia visiense a João de Barros? A falta de otro manuscrito que aclare la cuestión,

\footnotetext{
81. FARIA, 1655: 322.

82. VALE, 1970: 30-31.

83. MACHADO, 1741, vol. II: 333 .
} 
el callejón sin salida permanece y el argumento de Alexandre de Lucena e Vale debe ser visto con reservas. Aunque la frase apareciera en cualquier otro manuscrito, la autorreferencia podría aplicarse también al fraile Francisco Barreiros que indudablemente era nativo de Viseu.

\section{CONCLUSIÓN}

El esfuerzo por seguir cuidadosamente la trayectoria documental, así como la tarea de realizar el examen textual y visual de manuscritos e impresos, es importante para producir una hermenéutica más consistente, que considere el documento como un artefacto. Lejos de negar la autoría del Panegírico de D. João III y del Panegírico da infanta D. Maria atribuido a João de Barros, se observa que estos textos, tradicionalmente asociados a ese autor, traen consigo intervenciones que les son ajenas. Como hemos visto, José Barbosa y Manuel Severim de Faria intervinieron en los textos publicados, atribuyendo su autoría a João de Barros -cuyo nombre ya en aquellos siglos jugaba una «función» $»^{8}$.

Estas intervenciones pueden haberse sumado a otras muchas realizadas a lo largo del proceso de transmisión de copias manuales. Como los panegíricos pasaron a través de los siglos sin ser impresos, las copias manuscritas resultantes estaban sujetas a cambios debido a su condición «abierta». En el caso del Panegírico da infanta D. Maria, a pesar de que el único manuscrito conocido está en el ANTT, deben haberse realizado otras copias manuales. Según la descripción dada por el Conde de Ericeira sobre la copia del panegírico que formaba parte de la biblioteca de Manuel Severim de Faria, no es el mismo manuscrito depositado hoy en Torre do Tombo. En cuanto al Panegírico de D. João III, en las pocas palabras que dejó, José Barbosa afirma haber tratado con papeles desordenados. A partir de este material, organizó el texto con sus propias intervenciones y publicó la única versión conocida hoy en día del panegírico. Es difícil saber qué es propio de João de Barros y qué se añadió más tarde, ya que el registro más antiguo conocido del Panegírico de D. João III es el manuscrito depositado hoy en la BNP. Es muy probable que este manuscrito haya sido preparado por el propio Barbosa y haya servido de base para el texto editado en I740.

A diferencia del Panegírico de D. João III, el Panegírico da infanta D. Maria tiene un registro que no parece tener relación con el entorno de Manuel Severim de Faria. En este caso hay un manuscrito independiente y la hipótesis de que el editor Severim usó otro texto para su edición. Es posible determinar, dentro de los límites impuestos por los testimonios disponibles, las diferencias entre una versión y otra. La comparación de la edición de i655 del Panegírico da infanta D. Maria con el único manuscrito conocido del texto, depositado en el ANTT, concluye que el texto editado es mucho más extenso que el manuscrito. Por ejemplo, hay decenas de pasajes exclusivos de la edición de I655, algunos de los cuales son más pequeños y otros son

\footnotetext{
84. Foucault, (1969): 73-104.
} 
considerablemente más largos. También hay pasajes que solo se encuentran en el manuscrito, y pasajes que tratan del mismo tema, pero escritos de manera diferente en el manuscrito y en la impresión. Otro punto importante para destacar es el desplazamiento de los párrafos, que hace que la edición de I655 y la copia manuscrita presenten diferentes órdenes a cierta altura en sus textos.

En cuanto a los pasajes exclusivos del texto impreso, podemos atribuirlos al editor Manuel Severim de Faria. Sin embargo, a falta de otros manuscritos que puedan ser cotejados con esta copia de ANTT, la atribución deja de ser automática, ya que la copia utilizada por Severim podría traer esos pasajes. Por otra parte, el editor también puede haberlos escrito, según la práctica de la época, en la que completar $y$ añadir el original era un ejercicio frecuente. Debido a las dificultades de saber con certeza si tales pasajes son propios del autor intelectual o si fueron añadidos posteriormente, conclusiones como las de Alexandre de Lucena e Vale pueden ser cuestionadas, ya que el pasaje en el que el autor se basó para concluir el origen visiense de João de Barros solo se encuentra en el texto editado.

Los estudios que identifican el Panegírico de D. João III como la primera recepción de las ideas de Maquiavelo en Portugal también deben ser cuestionados. Teniendo en cuenta el largo intervalo que separa la composición de la impresión, a lo largo de los siglos se han podido añadir nuevos pasajes, incluyendo los extractos transcritos en su totalidad de textos como los Discorsi y Il Principe. Estos dos escritos de Maquiavelo se publicaron, respectivamente, en I53I y I532, y el Panegírico de D. João III se pronunció en I533. ¿Tendría João de Barros contacto con los textos de Maquiavelo poco después de que fueran impresos? ¿O habría leído versiones manuscritas de los escritos del florentino? La posibilidad de que estos pasajes hayan sido insertados en el supuesto texto original muestra cómo la historia intelectual y la crítica textual deben ser asociadas con la historia del libro y sus recepciones ${ }^{85}$.

Finalmente, no debemos perder de vista el hecho de que los panegíricos están diseñados para ser leídos. Las dificultades aumentan cuando se trata de reconocer las marcas de derecho de autor de un texto originado de un ejercicio oral o de un discurso / en la oralidad. Para Harold Love, no tiene mucho sentido ese tipo de búsqueda, pues textos como éste no están estructurados con vistas a su publicación, sino a su lectura, y el proceso de publicación pasa necesariamente por la supervisión del editor. La versión impresa de un evento oral no puede ser tratada como un registro transparente del contenido o del estilo del autor, porque la escritura puede haber sido hecha a partir de notas de alguien presente en el momento de la lectura del discurso, por ejemplo ${ }^{86}$.

Las historias de los dos panegíricos como artefactos deben entenderse a través de la compleja dinámica entre las comunicaciones orales y escritas ${ }^{87}$. Inicialmente, estos fueron concebidos como discursos orales y pronunciados ante asambleas. La oralidad consiste en la boca que habla y los oídos que escuchan, simultáneamente

\footnotetext{
85. JAUSS, 1994 [1967]; MCKENZIE 2005 [1999].

86. LOVE, 2002: 164-165.

87. BOUZA, (2002): 105-171.
} 
en el tiempo y en el espacio. Así se reconoce en el mismo Panegírico de D. João III: el «Panegírico faz sempre fé do que vê e o representa aos olhos» ${ }^{88}$, indicando la enunciación oral como propia de este género discursivo ${ }^{89}$. Inicialmente concebidos como discursos orales, los panegíricos sobrevivieron por sus registros escritos. Desde su composición y lectura hasta su publicación, sufrieron innumerables intervenciones. Sus sentidos literarios se construyeron con el tiempo, como resultado de las relaciones entre los elementos textuales y las acciones de varios agentes, según las tradiciones culturales y lingüísticas de cada época. Por lo tanto, el significado atribuido por João de Barros a los panegíricos pronunciados en el siglo XVI fue diferente de sus repercusiones en los siglos XVII y XVIII, momento en que fueron publicados por Manuel Severim de Faria y José Barbosa.

88. BARROS, 1943: 1.

89. BOUZA, 2004. 


\section{BIBLIOGRAFÍA}

\section{FUENTES IMPRESAS}

BArros, João de. Panegyricos do grande João de Barros. Fielmente reimpressos conforme sua antiga Linguagem $=$ ano de I533. Por Joaquim Francisco Monteiro de Campos Coelho, e Soiza, Lisboa, Na Oficina de António Gomes, I79I.

Barros, João de. Panegíricos (Panegírico de D. João III e da infanta D. Maria), ed. M. Rodrigues Lapa. Lisboa: Livraria Sá da Costa, I943.

Bem, D. Thomaz Caetano de. Memórias Historicas e Chronologicas da Sagrada Religiao dos Clerigos Regulares em Portugal e suas conquistas na India Oriental. Tomo II, Lisboa: na Regia Officina Typografica, I794.

Coleção dos documentos, estatutos e memórias da Academia Real da História Portuguesa, que neste ano de I72I, se compuseram e se imprimiram por ordem dos seus censores, dedicada a el rei nosso senhor, seu augustissímo protetor e ordenada pelo conde de Villamayor, secretário da mesma academia. Lisboa Ocidental, na oficina de Pascoal da Sylva, Impresso de S. Majestade real. MDCCXXI.

FARIA, Manuel Severim de. Discursos varios políticos. Em Evora: impressos por Manoel Carvalho, impressor da Universidade, I624.

FARIA, Manuel Severim d. Discursos vários políticos. Lisboa: Na Régia Officina Typografica, I777-I788, [I624].

FARIA, Manuel Severim d. Noticias de Portugal: offerecidas a El Rey N.S. Dom João o IV. / por Manoel Severim de Faria : declaaose as grandes commodidades que tem para crescer em gente, industria, comercio, riquezas, \& forças militares por már, 6 terra : as origens de todos os appellidos, \& as armas das familias nobres do Reyno : as Moedas que corrèrão nesta Provincia do tempo dos Romanos atè o presente : e se referem varios Elogios de Principes, \& Varoens Illustres Portugueses. Lisboa: na Officina Craesbeeckiana, I655.

FARIA, Manuel Severim d. Notícias de Portugal / escritas por Manoel Severim de Faria.... - $2^{\text {a }}$ Impressão / acrescentadas pelo padre D. José Barbosa. Lisboa Occidental: Off. de Antonio Isidoro da Fonseca, I740.

PACHeco, Miguel. Vida de la serenissima infanta doña Maria hija delRey D. Manoel, fundador de la insigne capilla mayor del Cõvento de N. Señora de la Luz, y de su hospital, y otras muchas casas dedicadas al culto divino. Lisboa: en la Officina de Juan de la Costa : a costa de Miguel Manescal Libreiro [sic] de S. Alteza, I675.

SousA, António Caetano de. Historia genealogica da casa real portugueza: desde a sua origem até o presente, com as Familias illustres, que procedem dos Reys, e dos Serenissimos Duques de Bragança : justificada com instrumentos, e escritores de inviolavel fé : e offerecida a El Rey D. João V, tomo I. Lisboa Occidental: na Officina de Joseph Antonio da Sylva, impressor da Academia Real, I737.

Sylva, Manoel Telles da. Noticias da Conferencia que a Academia Real da Historia Portugueza fez em 27 de abril de I724.

\section{FUENTES MANUSCRITAS}

ANTT, «Panegirico. A mui alta \& excellente princesa a iff. dona Maria», Colecção S. Vicente, livro I5. 
BNP, «Ao mui alto e muito poderosõ Rey de Portugal D. João 3o. deste nome Panegirico de João de Barros», cod. 3.060.

\section{REFERENCIAS BIBLIOGRÁFICAS}

AlbuQuerQue, Luís de. O Confronto do olhar o encontro dos povos na época das navegações portuguesas, séculos XV e XVI: Portugal, África, Ásia, América, Lisboa, Caminho, I99I.

AlBUQUERQUe, Martim de. Maquiavel e Portugal. Estudo de história das ideias políticas, Lisboa, Alêtheia, 2007.

Algranti, Leila Mezan. Megiani, Ana Paula Torres (eds.). O império por escrito: formas de transmissão da cultura letrada no mundo ibérico (séculos XVI-XIX, São Paulo, Alameda Editorial, 2009.

AlmeidA, Justino Mendes de. «Uma gramática latina de João de Barros», Euphrosine, (1959).

ANDRADE, António Alberto Banha de. João de Barros: historiador do pensamento humanista português de quinhentos, Lisboa, Academia Portuguesa da História, I980.

Boxer, Charles R. João de Barros, Portuguese humanist and historian of Asia, New Delhi, Concept Publishing Company, I98I.

Avelar, Ana Paula Menino. Visões do Oriente: formas de sentir no Portugal de Quinhentos, Lisboa, Edições Colibri, 2003.

BAIÃo, António (ed.). «Documentos inéditos sobre João de Barros, sobre o escritor seu homônimo contemporâneo, sobre a família do historiador e sobre os continuadores das suas 'Décadas'», Boletim da Segunda Classe da Academia das Sciencias de Lisboa. Vol. $\mathrm{XL}$, I917.

BAIÃo, António (ed. «Introdução», BARROS, João de. Ásia de Joam de Barros. Dos feitos que os portugueses fizeram no descobrimento e conquista dos mares e terras do oriente. Quarta edição revista e prefaciada por António Baião. Coimbra: Imprensa da Universidade, I998 [1932].

BARRETO, Luís Filipe. Descobrimentos e Renascimento: formas de ser e pensar nos séculos XV e $X V I$, Lisboa, Imprensa Nacional-Casa da Moeda, I982.

BARros, Jerônimo Duque Estrada de. Impressões de um tempo: a tipografia de Antônio Isidoro da Fonseca no Rio de Janeiro (I747-I750), Dissertação de Mestrado em História Social, Niterói, UFF, 2012.

Barros, Jerônimo Duque Estrada de. Na oficina de Antônio Isidoro da Fonseca: levantamento e análise das obras produzidas pelo primeiro tipógrafo da América portuguesa. Rio de Janeiro: Artículo publicado en línea en el sitio de la Fundação Biblioteca Nacional, 2012. Consultado el 25 de junio de 20I9. URL: https://www.bn.gov.br/en/node/I936.

BELO, André. As gazetas e os livros: a «Gazeta» e a vulgarização do impresso (I715-I760), Lisboa, Instituto de Ciências Sociais da Universidade de Lisboa, 200I.

Bezzi, Marina Thomé. Língua portuguesa e missionação no império português das Décadas de João de Barros (I552-I563), Dissertação de Mestrado em História Social, Rio de Janeiro, UFRJ, 20I4.

BIEDERMANN, Zoltán. «Nos primórdios da antropologia moderna: a Ásia de João de Barros», Anais de História de Além-Mar, (2003): 29-6I.

BouzA, Fernando. Del escribano a la biblioteca. La civilización escrita europea en la alta edad moderna (siglos XV-XVII), Madrid, Sintesis, I997. 
BouZA, Fernando. «Comunicação, conhecimento e memória na Espanha dos séculos XVI e XVII», trad. Ângela Barreto Xavier, Cultura. Revista de História e Teoria das Ideias, v. I9, $2^{\mathrm{a}}$ série, (I7I-I05:(2002.

BouzA, Fernando. Palabra e imagen en la corte. Cultura oral y visual de la nobleza em el Siglo de Oro, Madrid, Abada, 2004.

Buescu, Maria Leonor Carvalhão. Textos pedagógicos e gramaticais de João de Barros, Lisboa, Verbo, 1969.

CaStello-Branco, Fernando. «Portugal quinhentista visto através das cartilhas para ensinar a ler», Anais da Academia Portuguesa de História, (1973).

CHARTIER, Roger. A ordem dos livros: leitores, autores e bibliotecas na Europa entre os séculos XIV e XVIII, trad. Mary Del Priore, $2^{\text {a }}$ ed., Brasília, Editora da UnB, I998 [i994].

Chartier, Roger. A mão do autor e a mente do editor, trad. George Schlesinger, $\mathrm{I}^{\mathrm{a}}$ ed., São Paulo, Editora UNESP, 2014.

CIDADE, Hernani. «João de Barros - o que pensa da língua portuguesa - como a escreve», Boletim de Filologia, (1950): 28I-303.

CIDADE, Hernani. Portugal histórico-cultural, Lisboa, Arcádia, I968.

Coelho, António Borges. Tudo é mercadoria. Sobre o percurso e obra de João de Barros, Lisboa, Caminho, I992.

Coelho, António Borges. João de Barros: vida e obra, Lisboa, Grupo de Trabalho do Min. da Educação para as Comemorações dos Descobrimentos Portugueses, I997.

ConTl, Lígia Nassif. Um projeto pedagógico às margens da expansão: João de Barros e seu ideal moralizador, Dissertação de Mestrado em História Social, Franca, UNESP, 2005.

CRuz, Maria do Rosário Themudo Barata de Azevedo. As regências na menoridade de D. Sebastião. Elementos para uma história estrutural, vol. I, Lisboa, INCM, I993.

CurTo, Diogo Ramada [et all]. As gentes do livro: Lisboa, século XVIII, Lisboa, Biblioteca Nacional, 2007.

DiAs, J. S. da Silva. A política cultural na época de D. João III, Coimbra, Imprensa da Universidade, I969.

Foucault, Michel. «Qu’est-ce qu'un auteur?» Bulletin de la Société Française de Philosophie, (I969): 73-I04.

GouveıA, António Camões. «Teatinos», en Carlos Moreira Azevedo (ed.), Dicionário de História de Portugal, Lisboa, Círculo de Leitores, 200I.

HaHn, Fábio André. A pureza da fé. O antijudaísmo pacífico de João de Barros no Portugal Quinhentista, Tese de Doutorado em História Social, Niterói, UFF, 2009.

JAUSS, Hans Robert. A história da literatura como provocação à teoria literaria, trad. Sérgio Tellarori, São Paulo, Ática, 1967] 1994].

KLUCAS, Joseph A. «João de Barros: Erasmianism and the political image of king John III», Luso-Brazilian Review [En línea], 33-47 (I984). Consultado el 5 de agosto de 20I9. URL: https://www.jstor.org/stable/3513075? seq=I.

Laborinho, Ana Paula, Seixo, Maria Alzira e Meira, Maria José (eds.). A vertigem do Oriente: modalidades discursivas no encontro de culturas, Lisboa-Macau, Edições Cosmos/Instituto Português do Oriente, I999.

LAPA, Manuel Rodrigues. «Introdução», Barros, João de. Panegíricos (Panegírico de D. João III e da infanta D. Maria), Lisboa, Livraria Sá da Costa, I943.

Love, Harold. Attributing authorship: an introduction, Cambridge, University Press, 2002.

Marcoccl, Giusepe. A consciência de um império. Portugal e o seu mundo (sécs. XV-XVII), Coimbra, Imprensa da Universidade de Coimbra, 2012 [20II]. 
Mariguela, Adriana Duarte Bonini. Circularidade no século XVII: emergência da similitude na Cartinha de João de Barros e no Chatecismo de D. Diogo Ortiz, Tese de Doutorado em Educação, Campinas, UNICAMP, 20 Io.

Mckenzie, D. F. Bibliografía y sociologia de los textos, trad. Fernando Bouza. Madrid, Akal, 2005 [1999].

Megiani, Ana Paula Torres. O rei ausente: festa e cultura política nas visitas dos Filipes a Portugal (I58I-I6I9), São Paulo, Alameda, 2004.

Megiani, Ana Paula Torres. Cultura escrita e memória política no mundo ibérico. Séculos $X V$-XVII, Tese apresentada ao Departamento de História da Faculdade de Filosofia, Letras e Ciências Humanas da Universidade de São Paulo, para obtenção do Título de Livre-Docente, 2014.

MотA, Isabel Ferreira da. A Academia Real da História: os intelectuais, o poder cultural e o poder monárquico no século XVIII, Coimbra, Edições Minerva, 2003.

Oliveira, António de. «A infanta D. Maria e o Senhorio de Viseu: uma precisão cronológica», Revista Portuguesa de História, [En línea], 215-220 (I992). Consultado el 9 de agosto de 20I9. URL: https://digitalis-dsp.uc.pt/jspui/handle/I03I6.2/4638I.

PANEGassi, Rubens Leonardo. O pasto dos brutos: contexto de João de Barros, horizonte histórico e política nas «Décadas da Ásia», Belo Horizonte, Fino Traço, 2017.

Pereira, Manuel Botelho. Diálogos morais e políticos, Viseu, Junta da Província da Beira Alta, I955.

Pıchı, Luciana Stegagno. João de Barros: Diálogo em louvor da nossa linguagem, Modena, Società Tipografica Editrice Modense, I959.

Ramalho, Américo da Costa. Para a história do humanismo em Portugal, vol. I, Coimbra, INIC, I988.

RATTNER, Jair Norberto. Levantamento das obras impressas por António Isidoro da Fonseca existentes na Biblioteca Nacional de Lisboa, Lisboa, Universidade Nova de Lisboa, I990.

ReIs, Flávio Antônio Fernandes. A Prymera parte da cronica do emperador Clarimundo donde os Reys de Portugal descendem: retórica e ensinamento moral na crônica de João de Barros, Tese de Doutorado em Letras Clássicas e Vernáculas, São Paulo, USP, 2013.

RÉvAH, I. S. «O ‘Diálogo evangélico' de João de Barros», BARRos, João de. Diálogo evangélico sobre os artigos de fé contra o Talmud dos judeus. Manuscrito inédito de João de Barros, introdução e notas de I. S. Révah, Lisboa, Livraria Studium Editora, I950.

RÉVAH, I. S.. «Antiquité et christianisme anciens et modernes dans l'oevre de João de Barros», Revue Philosophique de la France et de l'Étranger [En línea], I65-185 (1967). URL: https:// www.jstor.org/stable/4IO94III?seq=I.

RÉVAH, I. S. «João de Barros». In: Études portugaises, Paris, Fundação Calouste Gulbenkian, I975.

RÉVAH, I. S. «Introdução», Ropica Pnefma. 2 Vols. Leitura modernizada, notas e estudo de Israel Salvator Révah, Lisboa, Instituto Nacional de Investigação Científica, I983.

Saraiva, António José e Lopes, Óscar. História da literatura portuguesa, Porto, Porto Editora, I996.

Saraiva, António José. Para a história da cultura em Portugal, vol. 2, Lisboa, Publicações Europa-América, 1972.

SERRÃo, Joaquim Veríssimo. A historiografia portuguesa, vols. Il e Ill, Lisboa, Verbo, I974.

SiLVA, Innocencio Francisco da. Diccionario bibliographico portuguez, tomo sexto, Lisboa, Imprensa Nacional, I962. 
SouzA, Bruno Omar. História, retórica e celebração imperial: João de Barros e a crônica ultramarina portuguesa do século XVI, Dissertação de Mestrado em História Social da Cultura, Rio de Janeiro, PUC, 2014.

VAle, Alexandre de Lucena e. No quarto centenário de João de Barros. Da verdadeira interpretação do «Panegírico da infanta» à naturalidade visiense do grande historiador, Viseu, Junta Distrital de Viseu, I970.

Vasconcelos, Carolina Michaelis de. A infanta d. Maria de Portugal (I52I-I577) e as suas damas. Pref. de Americo da Costa Ramalho, Lisboa, Biblioteca Nacional de Portugal, I983 [I902].

VicEnte, Carolina Pereira. Dois diálogos no renascimento português: João de Barros e Gândavo, Dissertação de Mestrado em Letras Vernáculas, Rio de Janeiro, UFRJ, 2008. 


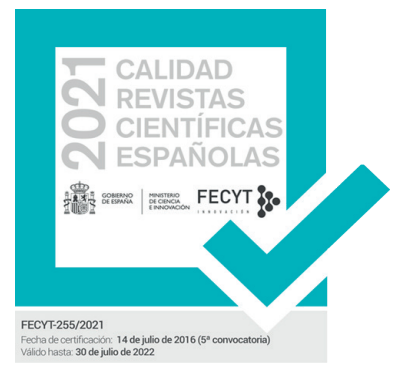

SERIE IV HISTORIA MODERNA

REVISTA DE LA FACULTAD DE GEOGRAFÍA E HISTORIA

AÑO 2021

ISSN: 1131-768X

E-ISSN 2340-1400

\section{4 \\ 西 ESPACIO, TIEMPO Y FORMA}

Monográfico - Special Issue: La política ultramarina de las monarquías ibéricas (circa 1700-1750): una historia de fracasos y éxitos relativos The Overseas Policy of the Iberian Monarchies (Circa 1700-1750): A History of Failures and Relative Successes

15 Roberto Quirós Rosado y MARIA FERnANDA BICALHO La política ultramarina de las monarquías ibéricas (circa 1700-1750): una historia de fracasos y éxitos relativos / The Overseas Policy of the Iberian Monarchies (Circa 1700-1750): A History of Failures and Relative Successes

\section{Guillaume Hanotin}

Defender negocios en tiempo de convulsión política: las elites mercantiles francesas durante la guerra de Sucesión española / Protecting Business in Time of Crisis: French Trademen during the War of Spanish Succession

\subsection{Maria Fernanda Bicalmo}

Ultramarino y el auge de los secretarios de Estado en Portugal durante la primera mitad del siglo XVIII / Sobre este modo de resolver e despachar os negócios. The decline of the Overseas Council and the Rise of the Secretaries of State in Portugal during the First Half of the $18^{\text {th }}$ Century

\section{9}

\section{VALENTINA FAVARò}

El fracaso de los proyectos de reforma en el virreinato peruano de principios

del siglo XVIII. Las propuestas de Carmine Nicola Caracciolo, príncipe de Santobuono the Eighteenth Century. The Proposals of Carmine Nicola Caracciolo, Prince of Santobuono

\section{7}

\section{ROBERTO QUIRÓS ROSADO}

Ecos de un mercantilismo truncado. El conde de Pinos Puente y la diplomacia comercial de Carlos VI en la corte de Lisboa (1723-1724) / Echoes of a Failed Mercantilism. The Count of Pinos Puente and the Commercial Diplomacy of Charles VI at the Court Of Lisbon (1723-1724)

\section{Junia Ferreira Furtado}

Portuguese America under Foreign Threat and the Creation of the Concept of uti possidetis in the First Half of the $18^{\text {th }}$ Century / La américa portuguesa bajo la amenaza exterior y la creación del concepto de uti possidetis en la primera mitad del siglo XVIII

\section{Miscelánea $\cdot$ Miscellany}

\section{José Antonio Mateos Royo}

con Cataluña / Trade Policy and Monetary Circulation in Aragon: Conflicts and Agreements with Catalonia (1535-1565)

\section{Fernando Altoé}

panegíricos atribuidos a la impresion. Un estudio de la trayectoria de dos the Trajectory of Two Panegyrics Attributed to João de Barros

\section{Francisco Velasco Hernández}

reino de Murcia (siglos XVI y XVII) / The Influence of the Berber Corsican on the Late Repopulation on the Coastal Area on the Kingdom of Murcia (XVI and XVII Centuries)

\section{José Antonio Martínez Martínez}

Criados, jornaleros y esclavos al servicio de la familia: la servidumbre de Serfdom of the Muñoz de Otálora in the $17^{\text {th }}$ Century

\section{Víctor Daniel Regalado González-Serna}

Benito de Medina a raíz de su ingreso en el cabildo catedral de Sevilla en 1669 / «Not a Single Good Portuguese». Accusations against Priest Alonso Benito de Medina when Entering the Cathedral Chapter of Seville in 1669

\section{José Herrera Reviriego}

organigrama comercial y militar de la Gober a tólo mitad del siglo XVII / "Only Time will Tell us»: The Role of Taiwan within the Commercial and Military Organization of the Philippine's Governoration during the First Half of the Seventeenth Century

\section{Manuel-Reyes García Hurtado}

de Rande, 1719-1733 / Vicissitudes of the Rescue Companies of the Sunken Ships in the Battle of Rande, 1719-1733

\subsection{Marcos de Miguel Muñoz}

Caballeros in 1769 


\section{4 ESPACIO, TIEMPO Y FORMA}

\section{Javier Tinoco Domínguez}

Tensiones sociopolíticas en el marco del catastro de Ensenada en Jerez de la Frontera: estudio de un conflicto institucional / Socio-Political Tensions within the Framework of Cadastre of Ensenada In Jerez de la Frontera: A Studying of an Institucional Conflict

\section{Pablo Fernández Albaladejo}

Fábulas de origen y gramática de nación en la España del siglo XVIII. A propósito de algunos trabajos de Francisco Martínez Marina / Origin's Fables and Grammar of Nation in the XVIII Century Spain. About some Works by Francisco Martínez Marina

\subsection{José María IÑURRITEgui Rodríguez}

Constitución increada: Francisco Martínez Marina y la crítica bíblica / Uncreated Constitution. Francisco Martínez Marina and Biblical Criticism

\subsection{David A. Abián Cubillo}

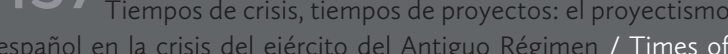
crisis, Times of Projects: The Spanish proyectismo during the Army's Crisis in the Ancient Regime

Taller de historiografía · Historiography Workshop

\section{Ensayos · Essays}

\subsection{ChrISTOPH ROSENMÜLLER}

«Tan peligrosas y feas conspiraciones»: la relación escrita por el embajador austriaco Christoph Migazzi en 1754 sobre la caída del marqués de la Ensenada / «Dangerous and Ugly Conspiracies». The Report of the Austrian Ambassador Christoph Migazzi on the Fall of the Marquis of la Ensenada in 1754

\subsection{Serge Gruzinskı}

Quelle histoire enseigner en 2021 ? / ¿Qué historia enseñar en 2021?

\subsection{Carlos Amate Pizarro}

Las relaciones hispano-chinas en el siglo XVI: síntesis e interpretación a la luz de la reciente historiografía / The Hispanic-chinese Relationship in the XVI Century: Synthesis and Interpretation in the Light of Recent Historiography

\section{Reseñas • Book Review}

521 Bolufer Peruga, Mónica, Arte y artificio de la vida en común. Los modelos de comportamiento y sus tensiones en el Siglo de las Luces, (Julio ArRoyo Vozmediano) 


\section{4 ESPACIO, TIEMPO Y FORMA}

525 Melón, Amando, Alejandro de Humboldt. Vida y obra (Carlos Martínez Shaw)

52 Commentary to Tatiana Seijas' review of The Atlantic World and the Manila Galleons: Circulation, Market, and Consumption of Asian Goods in the Spanish Empire (JosÉ LuIs GASCH TOMAS)

533 Braguier, Laurey, Servantes de dieu. Les beatas de la Couronne de Castille (1450-1600) (Manuela Águeda GARCÍA-GARRIDO)

539 Romeo, María CRuz; SAlomón, María Pilar; TABANERA, Nuria (eds.): Católicos, Reaccionarios y Nacionalistas. Política e identidad nacional en Europa y América Latina Contemporáneas (JAVIER M. Dos SANTOS)

54 Heredia López, Alfonso Jesús, El control de la corrupción en la Monarquía Hispánica. La Casa de la Contratación (1642-1660) (José Manuel Díaz Blanco)

17 Andújar Castillo, Francisco, El Atila de Madrid. La forja de un banquero en la crisis de la monarquía (1685-1715) (Aitor Díaz PAREdes)

551 Serrano Aviles, Javier y Mojarro, Jorge (eds.) Prada GonzALEZ, María (coord. de ilustraciones), En el archipiélago de la Especiería. España y Molucas en los siglos XVI y XVII (İ̃̃ıGo VALPUESTA VILLA)

555 Díaz Ceballos, Jorge, Poder compartido. Repúblicas urbanas, Monarquía y conversación en Castilla del Oro, 1508-1573 (JUAN SEbAstián Gómez GonZÁleZ)

51 Edelmayer, Friedrich, Massimiliano II, Filippo II I'Italia imperiale. II marchesato di Finale, i diritti imperiali e il «camino spagnolo» (RAFAEL VALLADARES)

56 Escribano-PÁEZ, José M., Juan Rena and the Frontiers of Spanish Empire, 1500-1540 (DAvid Martín Marcos)

56 ARnOLD, David, La Era de los Descubrimientos (1400-1600), Madrid, Alianza Editorial, 2021, 184 Pp., ISBN: 978-841362-172-2 (CARlos Amate Pizarro) 